\title{
Bioinspired cellulose-based membranes in oily wastewater treatment
}

\author{
Abdul Halim $(\bowtie){ }^{1}$, Lusi Ernawati ${ }^{2}$, Maya Ismayati ${ }^{3}$, Fahimah Martak $^{4}$, Toshiharu Enomae ${ }^{5}$ \\ 1 Department of Chemical Engineering, Universitas Internasional Semen Indonesia, Gresik 61122, Indonesia \\ 2 Department of Chemical Engineering, Kalimantan Institute of Technology, Balikpapan 76127, Indonesia \\ 3 Research Center for Biomaterials, National Research and Innovation Agency (BRIN), Bogor 16911, Indonesia \\ 4 Department of Chemistry, Faculty of Sciences, Sepuluh Nopember Institute of Technology, Kampus ITS Sukolilo, Surabaya 60111, Indonesia \\ 5 Faculty of Life and Environmental Sciences, University of Tsukuba, Tsukuba 305-8572, Japan
}

\section{H I G H L I G H T S}

- Cellulose-based membrane separates oily wastewater mimicking the living things.

- The three central surface mechanisms were reviewed.

- Preparation, performance, and mechanism are critically evaluated.

- First review of wettability based cellulose membrane as major material.

- The current and future importance of the research are discussed.

\section{A R T I C L E I N F O}

Article history:

Received 5 June 2021

Revised 29 October 2021

Accepted 5 November 2021

Available online 2 December 2021

\section{Keywords:}

Cellulose

Bioinspired membrane

Superhydrophobic surface

Underwater superoleophobic surface

Oil-water separation

\section{GR A P H I C A B S T R A T}

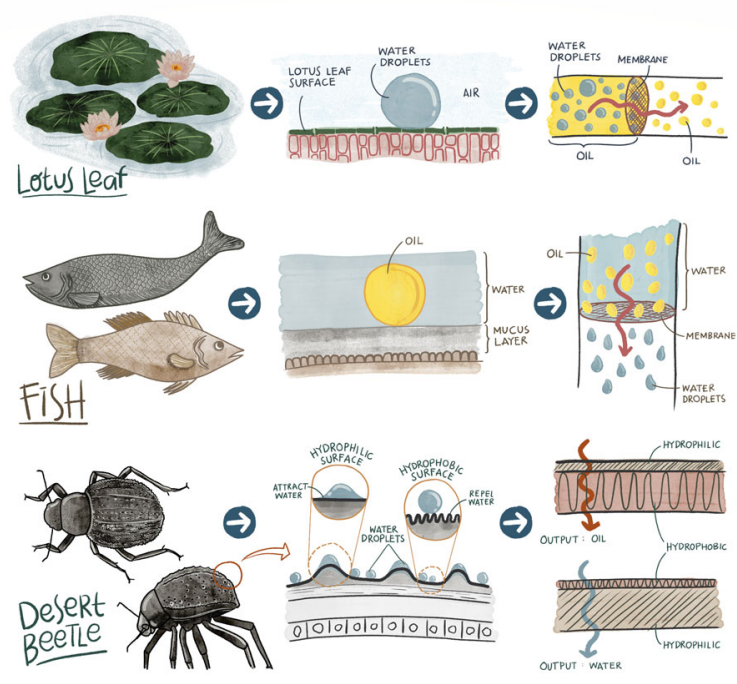

A B S T R A C T

It is challenging to purify oily wastewater, which affects water-energy-food production. One promising method is membrane-based separation. This paper reviews the current research trend of applying cellulose as a membrane material that mimics one of three typical biostructures: superhydrophobic, underwater superoleophobic, and Janus surfaces. Nature has provided efficient and effective structures through the evolutionary process. This has inspired many researchers to create technologies that mimic nature's structures or the fabrication process. Lotus leaves, fish scales, and Namib beetles are three representative structures with distinct functional and surface properties: superhydrophobic, underwater superoleophobic, and Janus surfaces. The characteristics of these structures have been widely studied and applied to membrane materials to improve their performance. One attractive membrane material is cellulose, which has been studied from the perspective of its biodegradability and sustainability. In this review, the principles, mechanisms, fabrication processes, and membrane performances are summarized and compared. The theory of wettability is also described to build a comprehensive understanding of the concept. Finally, future outlook is discussed to challenge the gap between laboratory and industrial applications.

(C) The Author(s) 2022. This article is published with open access at link.springer.com and journal.hep. com.cn
$凶$ Corresponding author

E-mail: abdul-halim.xm@alumni.tsukuba.ac.jp

\section{Introduction}

Water sanitization issues are related to the direct utilization of water itself, for example for drinking or household use, 
and food production and energy issues, otherwise known as the food-water-energy nexus (Scanlon et al., 2017; D'Odorico et al., 2018; Kibler et al., 2018). Polluted water endangers animals and decreases agricultural production, threatening the food stock. Dangerous chemicals dissolved in irrigation water may enter the plant body and eventually contaminate the food chain system. Even an improvement in the watering practice of a rice field can decrease agricultural methane as a source of greenhouse gas significantly (Runkle et al., 2019). Food production itself accounts for $70 \%$ of freshwater withdrawal and $90 \%$ of freshwater consumption (Siebert et al., 2010). Conversely, arbitrary food consumption, production processes, and global food chain delivery threaten the global surface water (D'Odorico et al., 2018).

In regard to energy issues, turbine generators, water cooling systems, and oil and gas excavation consume water. The consumption of the energy sector is much less than the food sector. Globally $\sim 15 \%$ of water is withdrawn, and $11 \%$ is consumed (Scanlon et al., 2017). Conversely, water has the inherent capability to dissolve many types of materials causing water to be easily contaminated. Purifying this wastewater requires several separation steps, consuming a large amount of energy. However, increasing industrial activities, oil exploration, and oil spill accidents decrease the quality and increase the quantity of wastewater, and threaten the aquatic ecosystem. Currently, existing oily wastewater treatments, for example using an open lagoon or centrifugation, require a large amount of space and long residence times. Simultaneously, centrifugation requires intensive energy consumption before reaching the maximum allowable limit specified in the standard of biological oxygen demand (BOD)/ chemical oxygen demand (COD) (Nasution et al., 2018). The advantages and disadvantages of several separation methods are resumed in Table 1 (Rasouli et al., 2021).

The surface interaction-based membrane has been introduced to overcome the limitations mentioned above (Table 1). Surface interaction is based on selective wettability through a hydrophobic/hydrophilic interaction between the surface membrane and solute (Padaki et al., 2015). A wide range of surface interaction-based membrane materials and their fabrication techniques have been intensively studied, for instance, metal mesh (Yang et al., 2019a; Zhu et al., 2020), carbon nanotube (CNT) (Hsieh et al., 2016; Saththasivam et al., 2018), graphene oxide (GO) (Wang et al., 2015a), synthetic polymers (Miao et al., 2020; Wang et al., 2020a), biopolymers-derived carbon (Yue et al., 2018a), Carbon nanofiber (Noamani et al., 2019), and biopolymer, including chitosan (Li et al., 2019a), alginate ( $\mathrm{Li}$ et al., 2017b), and cellulose (Halim et al., 2019). The surface interaction-based membrane shows higher separation performance than conventional membrane (Wu et al., 2018, Guo et al., 2019, Yi et al., 2019).

Cellulose is the most abundant natural polymer, sustainable, and not in competition with the food supply. Currently, the primary source of commercial cellulose is extracted from wood or cotton. However, cellulose also can be obtained from various sources such as agricultural waste (Suhas et al., 2016; Thakur and Voicu, 2016). In 2013 itself, cellulose-based polymers are $61.8 \%$ of biobased polymers (Shaghaleh et al., 2018). The utilization of cellulose, either fully or partially in membrane application, attracts many researchers (Tan et al., 2020). Life cycle assessment shows that biobased polymers membrane combined with environmentally friendly processes reduce environmental impact (Foroughi et al., 2021; Yadav et al., 2021).

Surface interaction-based separation using cellulose membranes is divided into three categories: hydrophobic, hydrophilic, and Janus. The various sustainability and biodegradability characteristics of cellulose as a polymer are advantageous to cellulose products. Several reviews of

Table 1 Comparison of separation methods in oily wastewater treatment. Reproduced with permission (Rasouli et al., 2021). Copyright 2021,

Elsevier

\begin{tabular}{|c|c|c|}
\hline Separation method & Disadvantages & Advantages \\
\hline Adsorption & $\begin{array}{c}\text { Low hydrophobicity, high water uptake, high retention } \\
\text { time, low efficiency, and secondary pollutant in } \\
\text { regeneration stage }\end{array}$ & $\begin{array}{l}\text { Low chemicals consumption, high removal of oil and chemical oxygen } \\
\text { demand, low cost, low-energy consumption, natural sorbents are } \\
\text { environmentally friendly }\end{array}$ \\
\hline Coagulation & $\begin{array}{l}\text { High operating costs, secondary pollution problem, } \\
\text { skilled operator dependent and composition dependent }\end{array}$ & $\begin{array}{l}\text { Good separation, flexibility to be combined with floatation for higher } \\
\text { separation efficiency }\end{array}$ \\
\hline Electrocoagulation & $\begin{array}{l}\text { High investment cost, anode passivation, high energy } \\
\text { consumption }\end{array}$ & Effective separation, simple operation, economical \\
\hline Filtration & High energy demand, high operating costs, fouling & Fast separation, pressure dependent \\
\hline Centrifugation & $\begin{array}{l}\text { Produces low-quality oil, high energy demand, } \\
\text { fouling, time-consuming, space limitations, expensive } \\
\text { maintenance }\end{array}$ & Efficient for free and dispersed oil, fast separation \\
\hline Gravity settling & $\begin{array}{l}\text { Not efficient for high-density oil, time-consuming, } \\
\text { space limitations }\end{array}$ & Separation of bulk oils, economical, low energy consumption \\
\hline Gas flotation & Requires large air volume, slow separation & Effective separation, energy efficient, simple operation \\
\hline
\end{tabular}


membrane-based methods on wettability have been conducted. For instance, Miller et al. reviewed several techniques to engineer the surface wettability of common polymeric membranes (Miller et al., 2017; Zarghami et al., 2019). More generally, Wang et al. (2016c) reviewed environmental applications based on wettability characteristics of the surface. Applications include anti-biofouling, enhanced vapor condensation and distillation, and water harvesting. Reviews of underwater superoleophobic membranes and in-air superhydrophobic membranes from all kinds of materials have been published (Chu et al., 2015; Brown and Bhushan, 2016; Lv et al., 2021; Sam et al., 2021), including their design, fabrication, and separation mechanisms.

Furthermore, the theoretical principles of surface wettability and its biomimicking properties have been reviewed (Nishimoto and Bhushan, 2013; Liu et al., 2013, 2014; Bellanger et al., 2014; Wang et al., 2015c; Zhang et al., 2017b). Ma et al. (2016) specifically reviewed two types of materials with their surface wettability modified: filtration-based membranes and absorption-based absorbents. A review of cellulose membranes, in general, was conducted by Thakur and Voicu (2016) and Tan et al. (2020). Even though reviews on cellulose-based materials exist (Teisala et al., 2014; Liu et al., 2016a; Li et al., 2017a), the focus remains on superhydrophobic membranes. Hence, we will review bio-mimicking technology research using cellulose as either a supporting or active material in its application as an oil-water separator. This review exclusively handles cellulose of which a significant proportion is comprised of supporting materials or which plays a significant role as an active material. The cellulose properties vary widely with their source. However, this variation is due to the differences in how cellulose polymers are packed and assembled. At the molecular level, it is common knowledge that cellulose is a polymer of glucose through 1,4 $\beta$-glycosidic bonds. This review deals with cellulose from all sources.

However, we excluded cellulosic materials applied only for matrix reinforcement and significantly modified cellulose by introducing functional groups, including nitrocellulose and cellulose acetate. We included the cellulose nanocrystal (CNC) and 2,2,6,6-tetramethylpiperidine-1-oxylradical (TEMPO) oxidized cellulose nanofiber, TOCNF in this review as the sulfate group on $\mathrm{CNC}$ or carboxylic group on TOCNF is not the main purpose of synthesis but solely a side effect. This review will discuss the theory of water-wettability of cellulosic materials followed by the principles, mechanisms, preparation, and performance of superhydrophobic, superoleophobic, and Janus-based membranes consecutively. Organisms and their plant or animal-mimicking surface characteristics will be discussed in each sub-topic, followed by a description of how fabrication methods, material selection, and performance evaluation were applied.

\section{Wettability}

The wettability of a surface determines the efficacy and mechanisms of separation; whether it absorbs or repels oil. Surfaces with special wettability of certain liquids are referred to as a combination of "liquid + philic" if the surface attracts the liquid, and "liquid + phobic" if the surface repels the liquid. For example, hydrophobic, oleophobic, and hemophobic are used to refer to water, oil, and blood repelling surfaces, respectively. The Greek word "amphi" is also used to indicate that the surface acts the same way to both oil and water. However, amphiphobic is exaggerated as, in the air, oleophobic automatically becomes hydrophobic. The contact angle is the most simple and direct method to measure the wettability of a surface (Michel et al., 2001; Gupta et al., 2019). Young (1805) proposed that the contact angle of a liquid on a solid surface depends on the liquid surface tension, the surface energy of the solid, and the interfacial tension between the solid and liquid, as shown in Fig. 1(a). When the liquid is static, Newton's second law can be applied to obtain the contact angle using the equation shown in Eq. (1) (Young, 1805):

$$
\cos \theta=\frac{\gamma_{S A}-\gamma_{S L}}{\gamma_{L A}}
$$

where $\gamma$ is the interfacial tension, and subscripts $S, A$, and $L$ correspond to the solid, vapor, and liquid phases, respectively. The contacted surface area influences the interaction between the solid and liquid. Therefore, on a rough surface with a larger area, the interaction becomes stronger (Fig. 1(b)). If $r$ is roughness defined as the ratio between the total surface area to the projected surface area, the apparent contact angle equation is expressed by the Wenzel equation as shown in Eq. (2) (Wenzel, 1949):

$$
\cos \theta_{W}=r \cos \theta,
$$

where $\theta_{W}$ is an apparent contact angle in the Wenzel state. The roughness of itself ranges from macroscopic to molecular scale (Youngblood and McCarthy, 1999; Huang and Gates, 2020). As the liquid droplet is smaller than the microscale groves, the drop will receive interfacial surface energy and roughness corresponding to the surface. Therefore, several attempts have been introduced to create nano to microscale roughness (Nosonovsky and Bhushan, 2007; Cho and Choi, 2008; Jeong et al., 2009; Cha et al., 2010; Li et al., 2013; Chen et al., 2015; Jiang et al., 2017; Sun et al., 2019).

A void may exist between the solid surface and the liquid, thus decreases the solid-liquid contact area (Fig. 1(c)). The composite condition increases the apparent contact angle mathematically expressed by the CassieBaxter equation (Cassie and Baxter, 1944), as shown in Eq. (3). 

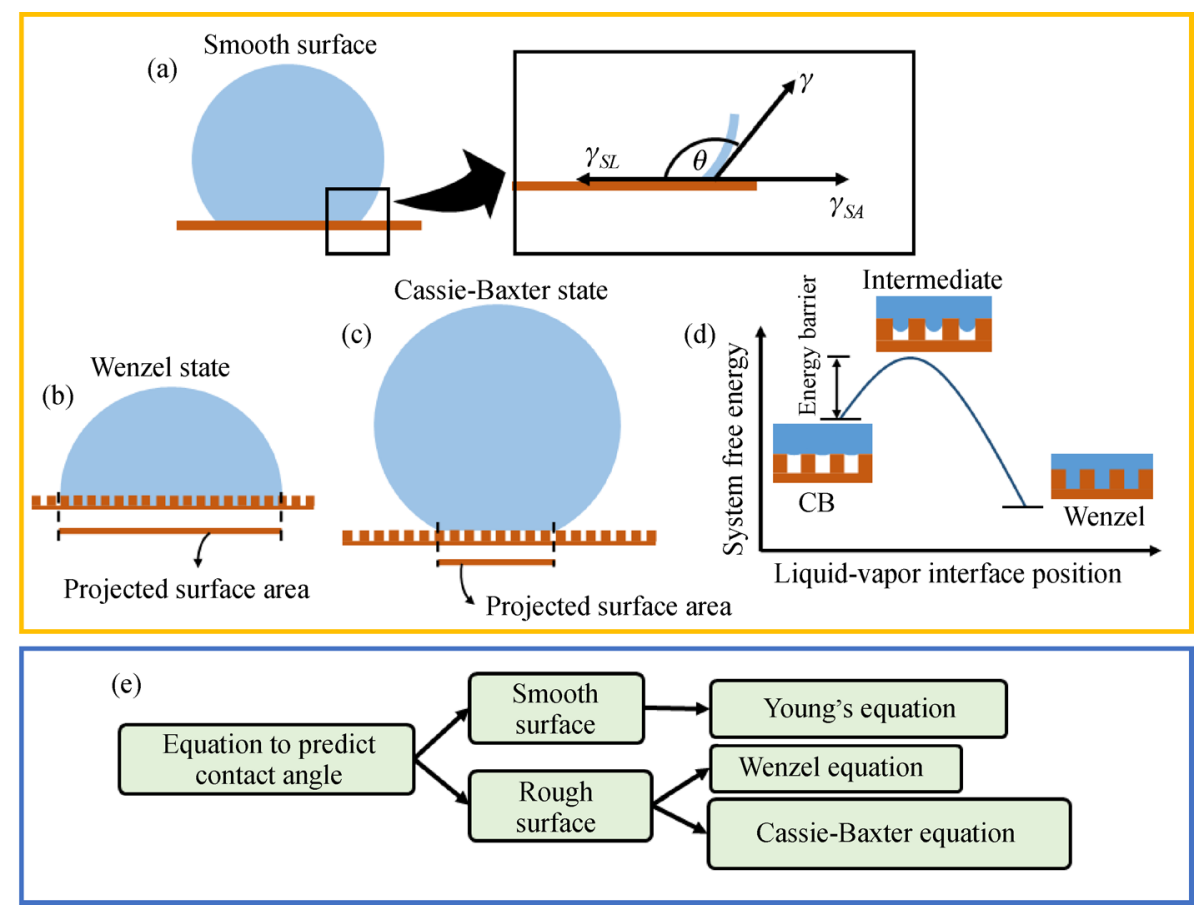

Fig. 1 (a) Contact angle of a smooth surface and the forced employment in its three interfaces, (b) Wenzel state, (c) Cassie-Baxter state, (d) Illustration of system free energy as a function of liquid-vapor interface, and (e) Infographic of the equation to predict contact angle.

$$
\cos \theta_{C B}=f_{S L} \cos \theta_{0}-f_{L A},
$$

where $\theta_{C B}$ is the apparent contact angle in the CassieBaxter state and $f_{S L}$ and $f_{L A}$ are the area fraction of the solid-liquid and liquid-air interfaces, respectively. As the void is filled with vapor, the Cassie-Baxter state is thermodynamically metastable. In contrast, Wenzel's state is considered to be stable (Murakami et al., 2014). However, some energy transition is applied to push the Cassie-Baxter state to the Wenzel state, as illustrated in Fig. 1(d). The summary of which equation to predict contact angle is depicted in Fig. 1(e).

Figure 2 shows several characteristics of the surface. When a sessile drop of water comes into contact with a hydrophilic surface, it spreads out on the surface and sticks to it. Conversely, a superhydrophobic surface spontaneously makes a water droplet spherical and roll down. However, the superhydrophobic surface may have a high contact angle and be sticky, for example the surface of a rose petal (Bhushan and Nosonovsky, 2010). Some surfaces also have a low contact angle and are slippery, for example a Nepenthes pitcher (Wong et al., 2011; Semprebon et al., 2017) (Fig. 2(a)). The minimum angle of tilting for the droplet to roll is referred to as the roll-off or sliding angle $\left(\theta_{S}\right)$, which is approximately similar to the hysteresis angle, or the difference between receding and advancing angles (Fig. 2(b)). The receding angle $\left(\theta_{R}\right)$ is the minimum angle at which the droplet volume decreases, while the advancing angle $\left(\theta_{A}\right)$ is the maximum angle at which the droplet volume increases. The measurement of receding and advancing angles is shown in Fig. 2(c). The volume of an attached droplet increases for advancing contact angles and decreases for receding contact angles, maintaining a stable contact line but with an unstable contact angle. The droplet continues to reduce and advance, transferring the contact line and maintaining a stable contact angle, which is a true receding and advancing contact angle (Korhonen et al., 2013).

As membranes for oil-water separation are usually applied in underwater environments, modifications needed to be made to Eqs. (1)-(3) to accommodate for the interfacial tension between water, oil, and a solid membrane surface. Therefore, Young's equation was modified for water environments as follows (Eqs. (4)-(7)):

$$
\begin{gathered}
\gamma_{S A}=\gamma_{O S}+\gamma_{O A} \cos \theta_{O A}, \\
\gamma_{S A}=\gamma_{W S}+\gamma_{W A} \cos \theta_{W A}, \\
\gamma_{S W}=\gamma_{O S}+\gamma_{O W} \cos \theta_{O W}, \\
\cos \theta_{O W}=\frac{\gamma_{O A} \cos \theta_{O A}-\gamma_{W A} \cos \theta_{W A}}{\gamma_{O W}},
\end{gathered}
$$

where subscript $O$ and $W$ refer to oil and water, respectively. Equation (7) is a rearrangement of Eqs. (4)(6) (Liu et al., 2009). As this equation is derived from Young's equation, it is only applicable to smooth, chemically homogeneous surfaces. However, several surface properties of materials change depending on the 


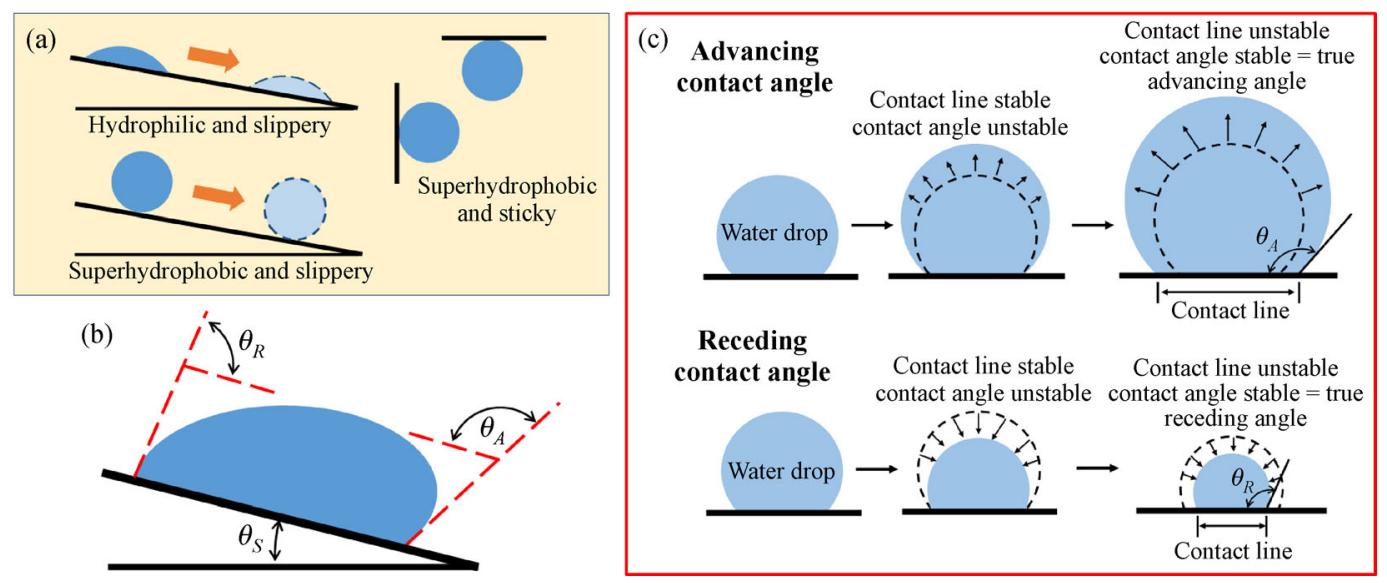

Fig. 2 (a) Several types of surface properties, (b) illustration of a receding contact angle, advancing contact angle and sliding contact angle, (c) measurement of an advancing and receding contact angle.

environment especially zeta potential for cellulose-derived materials (Cheng et al., 2017a). Due to the surface of oil droplets tend to be positively charged under water environment, the repellency increases significantly to the positively charged surface such as the surface of TEMPOoxidized cellulose nanofiber (Halim et al., 2020a).

Depending on the surface characteristics, three approaches (an oleophobic, hydrophobic, or Janus membrane) were applied to separate an oil-water mixture or emulsion. Hydrophobic and oleophobic membranes refer to those with surfaces with water or oil contact angles above $90^{\circ}$. Whereas superhydrophobic and superoleophobic membranes refer to those with water or oil contact angles of $150^{\circ}$ or higher.

\section{Superhydrophobic surfaces}

\subsection{Principles and mechanisms}

The lotus leaf is a natural example of a superhydrophobic surface and has a wax layer on its surface (Wang et al., 2009; Ensikat et al., 2011). The roughness of the lotus leaf on a microscopic scale enhances its hydrophobicity (Fig. 3 (a)). Low sliding angles make it easy for water droplets to roll and sweep up all residues of dust on the leaf's surface, keeping the lotus leaf perpetually clean.

Superhydrophobic oily wastewater remediation technology mimics the inherent properties of the lotus leaf surface. The superhydrophobicity of the surface is the simplest of three major mechanisms. Water has a higher surface tension than most organic oils. Based on Young's equation, the water contact angle is almost always higher than the oil contact angle (Tuteja et al., 2007). A superhydrophobic surface is effective in the separation of water-in-oil systems. Oil will penetrate the membrane due to its higher affinity than water, as shown in Fig. 3(b). Based on this mechanism, superhydrophobic membranes are, therefore, an appropriate method for separating water-in-oil mixtures or emulsions. The food industry is currently dealing with palm oil effluents as one industry which uses water-in-oil systems.

\subsection{Preparation of superhydrophobic membranes}

\subsubsection{Cellulose as a supporting material}

Due to cellulose's hydrophilic nature, as a supporting material it is modified to be non-polar, for example through esterification with acetate, or coated to become hydrophobic. In general, cellulosic materials, such as cellulose aerogel or sponge, are processed by coating, mixing, or combining them with nanoparticles or active materials to increase their roughness or to add various unique properties. Supporting materials with a high degree of roughness may not require a roughness enhancer. Cellulosic products that have been reported as supporting materials include paper (Wang et al., 2010; Cheng et al., 2017c; Zhang et al., 2020a; Xu et al., 2021), woven (Zhang et al., 2013; Cheng et al., 2017c; Zahid et al., 2017) and non-woven fabrics (Han et al., 2018), sponges (Peng et al., 2016a), and aerogel (Zhou et al., 2018; Li et al., 2019c). In general, cellulose as a supporting material is classified into three types: 3D porous structures (sponge or aerogel), fabrics (woven or non-woven), and paper (Fig. 4(a)). The $3 \mathrm{D}$ porous superhydrophobic membranes purify wastewater by absorbing oil until it is saturated. Then, the oil will pass through the membrane pores. However, some cellulosic paper or cotton fabrics applied only as an absorbent, have also been reported to separate oil-water emulsions (Han et al., 2018; Li et al., 2019c; Zhang et al., 2020a).

Aerogel has longer permeating channels, but the fabrication process is complicated. The production process 
(a)



(b)

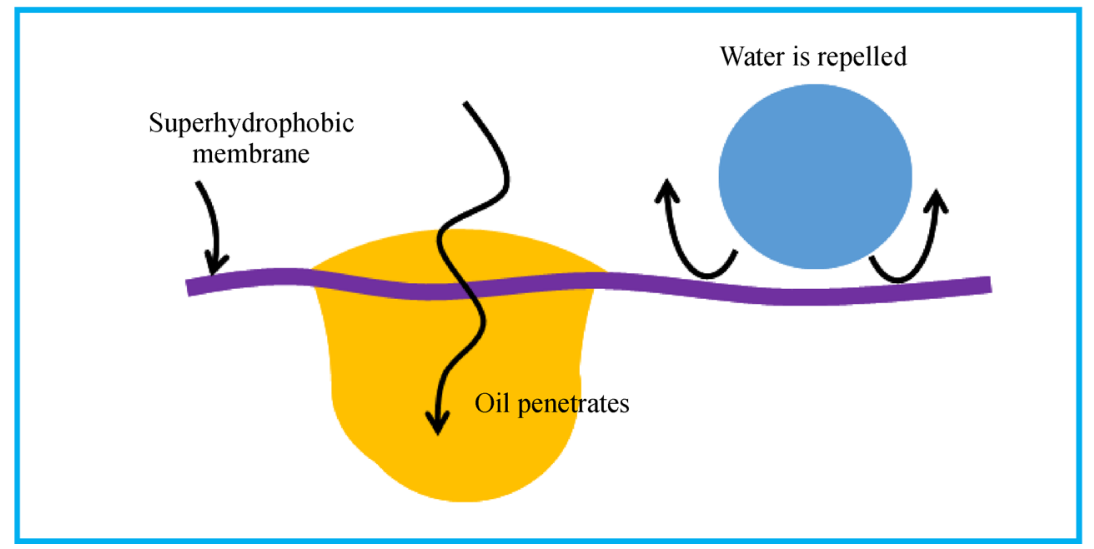

Fig. 3 (a) The surface morphology of the lotus leaf consists of rough microscale groves and nanoscale tubes. The tubes consist of wax layer. (b) Separation mechanism of the superhydrophobic membrane. (a) Reproduced from (Ensikat et al., 2011) Copyright 2011, Beilstein-Institut.

to produce paper as a filter material is simple. However, paper has low physical strength and is limited only to laboratory use, testing, and small instruments. On the other hand, both woven and non-woven cotton fabrics provide greater physical strength compared to paper or sponge membranes. SEM images of several types of membranes are shown in Figs. 4(b)-4(f).

Sponges and aerogel as supporting materials are produced from cellulose by dissolving or dispersing cellulose followed by regeneration. The mixture of sodium hydroxide and urea (Peng et al., 2016a), $\mathrm{NaClO}_{2}$, and acetic acid ( $\mathrm{Li}$ et al., 2019c) is used as a cellulose solvent. Another review (Wang et al., 2016b) describes in more detail cellulose solvents and dissolution. For the electrospinning fabrication method, the porous structure of a sponge is generated by a foaming agent, as the electrostatic force produces only two-dimensional cellulose fiber mats. A use of $\mathrm{CaCO}_{3}$ was reported for template pore formation by $\mathrm{CO}_{2}$ gas generation (Peng et al., 2016a; Meng et al., 2020).

Furthermore, the aerogel form provides the function of not only oil filtration but also oil or organic liquid absorption. The light and robust structure of aerogel are excellent properties for an oil absorbent. However, the fabrication method of aerogel is complicated and requires advanced instruments. Direct freeze-drying of a cellulose solution (Peng et al., 2016a; Li et al., 2019c; Meng et al., 2020), and electrospinning followed by gas-forming then freeze-drying have also been reported to produce aerogel (Li et al., 2019c). Solely solvent exchange failed to 
produce high enough porosity or surface area. N'methylenebisacrylamide (MBA) (He et al., 2021), or epichlorohydrin (Peng et al., 2016a), was used as a crosslinking agent between cellulose fiber.

Commercial cotton woven fabrics are commonly used due to their superiority of physical strength compared to paper and cellulosic aerogel. Non-woven-based superhydrophobic membranes are generally made from synthetic materials (Gu et al., 2017; Zhang et al., 2019a, $2019 \mathrm{~b}$ ) or cellulose derivatives such as cellulose acetate (Arslan et al., 2016). Cellulose solvent limitations and the complicated process hinder the usage of non-woven based fabrics as a superhydrophobic membrane. Hence, nonwoven fabrics are usually used as superoleophobic membranes, where the cellulose membrane is fabricated by dissolving and regenerating it to obtain its nanostructure. The structure of woven cotton facilitates active material development by the coating chemicals' deep penetration of every single cotton fiber (Zhou et al., 2013). Hence, even physical damage caused by stretching does not decrease its superhydrophobicity. For example, polyaniline (PANI) coated cotton and $1 \mathrm{H}, 1 \mathrm{H}, 2 \mathrm{H}, 2 \mathrm{H}$-perfluorooctyltriethoxysilane $\left(\mathrm{C}_{14} \mathrm{H}_{19} \mathrm{~F}_{13} \mathrm{O}_{3} \mathrm{Si}\right)$ (PTES) coated cotton demonstrate strong superhydrophobicity even after stretching or scratching (Zhou et al., 2013).

\subsubsection{Coating of superhydrophobic membranes}

\subsubsection{Particle coating}

The coating of superhydrophobic membranes consists of particles as rough enhancers and/or polymers to change the surface wettability from hydrophilic to hydrophobic
(Fig. 5(a)). Two types of coating materials are applied after regeneration or during dissolution, i.e., particles to enhance roughness or polymers as active materials. The hierarchical structure of aerogel on a nano- to micro-scale ensures positive results of surface hydrophobization. Meso- to micro-scale particles are deposited on the surface of the substrate to increase the roughness. The particles may be synthesized or commercial particles used, as depicted in Figs. 5(b) and 5(c). Common particles used are silicon oxide $\left(\mathrm{SiO}_{2}\right)$ (Han et al., 2018), Zinc Oxide ( $\left.\mathrm{ZnO}\right)$ (Zhang et al., 2013; Cheng et al., 2017c), Iron oxide $\left(\mathrm{Fe}_{3} \mathrm{O}_{4}\right)$ (Peng et al., 2016a; He et al., 2021), $\mathrm{TiO}_{2}$ (Yang et al., 2019b; Wang et al., 2020b; Arumugam et al., 2021), AlOOH (Yue et al., 2018b) or $\mathrm{Cu}$ nanoparticles (Li et al., 2019c). These metal oxide nanoparticles increase the roughness and embody additional functions in the membrane. For instance, $\mathrm{TiO}_{2}$ nanoparticles' capability to catalyze organic breakdown can be used to enhance the membrane's self-cleaning function under UV irradiation (Kettunen et al., 2011). $\mathrm{TiO}_{2}$ also has the function of switching surface properties from hydrophobic to hydrophilic and vice versa. The high surface area of CNF aerogel facilitates weight gain of coatings on the surface. In comparison, $\mathrm{CNF}$ aerogel contains $8 \%-8.6 \% \mathrm{TiO}_{2}$, while a $\mathrm{CNF}$ film and filter paper may contain only $0.3 \mathrm{wt} \%$ and $0.9 \mathrm{wt} \% \mathrm{TiO}_{2}$, respectively. The $\mathrm{TiO}_{2}$-coated CNF aerogel showed hydrophobicity, but hydrophilicity after UVirradiation, and then changed back to hydrophobic after storage in the dark for two weeks (Kettunen et al., 2011). Meanwhile, $\mathrm{Fe}_{3} \mathrm{O}_{4}$ is mainly used for its magnetic properties and anti-bacterial activities. A sponge coated with $\mathrm{Fe}_{3} \mathrm{O}_{4}$ can be moved freely by magnetic force in order to absorb oil (Peng et al., 2016a).

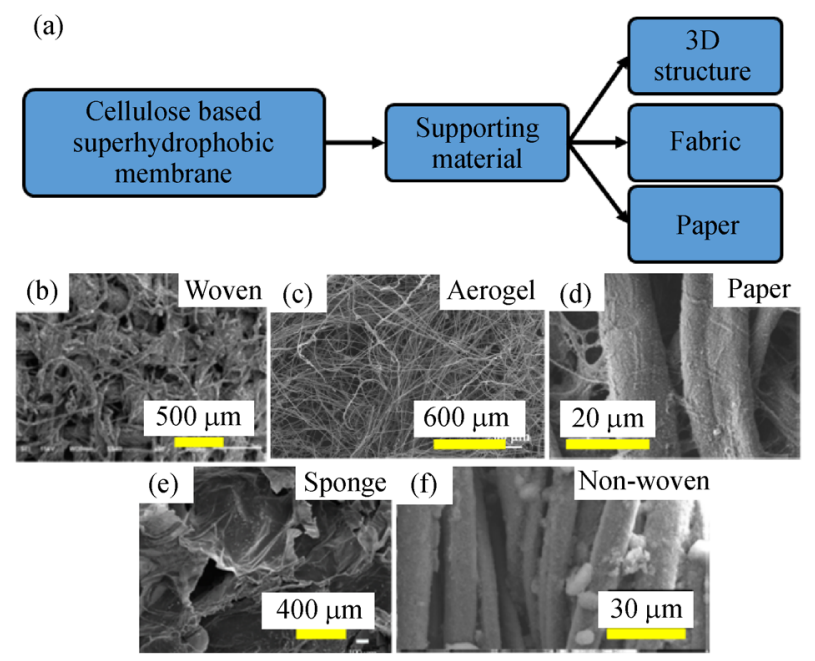

Fig. 4 Schematic diagram of cellulose as a supporting material in a superhydrophobic membrane (a). Scanning electron microscopy (SEM) of several cellulose-based membranes, i.e., woven fabric (b), aerogel (c), paper (d), sponge (e), and non-woven fabric (f). (b) Reproduced with permission. (Cheng et al., 2017c) Copyright 2017, American Chemical Society. (c) Reproduced with permission. (Li et al., 2019c) Copyright 2019, American Chemical Society. (d) Reproduced with permission. (Wang et al., 2010) Copyright 2010, American Chemical Society. (e) Reproduced with permission. (Peng et al., 2016a) Copyright 2016, American Chemical Society (f) Reproduced with permission. (Han et al., 2018) Copyright 2018, American Chemical Society. 
(a)



(b)

Particles are synthesized

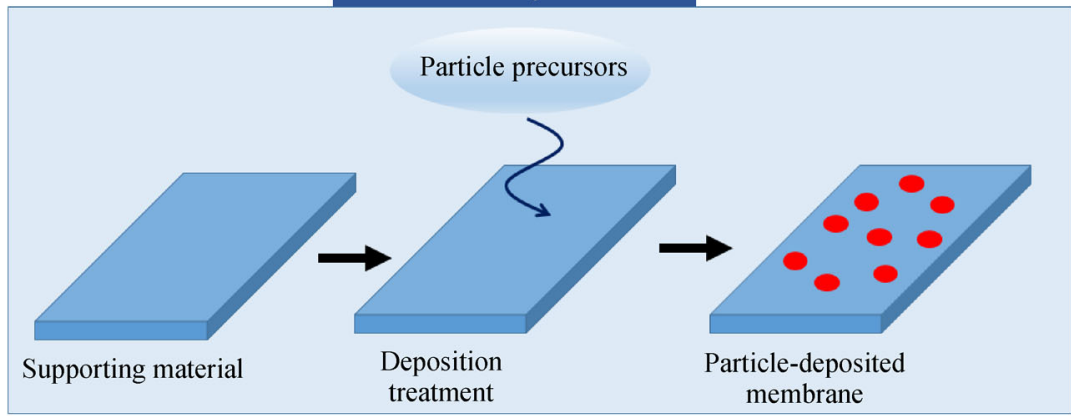

(c)


Fig. 5 (a) Diagram of coating types for superhydrophobic membranes. The coating particles could be either synthesized (b) or ready particles (c). The scanning electron microscopy of pure cotton fabric (d) directly absorbs water (insert of d). After coating (e), the fabric shows a superhydrophobic surface with a high water contact angle (insert of e). The structure of particles resembles a marigold flower (f). (d-f) Reproduced with permission (Huang et al., 2015). Copyright 2015, Royal Society of Chemistry.

Although the particles increase the surface roughness and enhance the surface affinity, too high concentrations negatively affect the contact angle. The optimum fly ash concentration is reported to be $0.5 \mathrm{wt} \%$. However, a higher concentration than $1.25 \mathrm{wt} \%$ decreases the contact angle from $152^{\circ}$ to $115^{\circ}$ (Wang et al., 2016a). Higher concentrations decrease adhesion strength due to particle aggregation. The statistical approach has been employed to obtain optimal conditions of the particles deposited on the surface (Zhang et al., 2020b).

The nanoflower (Huang et al., 2015) or nanoneedle (Wang et al., 2017b) is usually more desirable, as it provides higher roughness and is better at trapping air in the void of the membrane surface than spherical forms. Using nanoparticle deposition on the aerogel surfaces, the surface area increases from 28.3 to 94.8 to $108.6-195.5$ $\mathrm{m}^{2} / \mathrm{g}$ (Zhou et al., 2018). Interestingly, the aerogel successfully separated not only oil-water mixtures but also oil-in-water emulsions.

Several techniques, including dip coating (Cheng et al., 2017c), simple immersion (Wang et al., 2010; Xu et al., 2021), chemical precipitation (Peng et al., 2016a; Li et al., $2019 \mathrm{c}$ ), and chemical vapor deposition (Kettunen et al., 2011; Zhou et al., 2013), were applied to deposit the nanoparticles or polymers. Dip coating and simple immersion usually use commercially-available particles (Khan et al., 2018) with different shapes and sizes for each product. Nanoparticles synthesized through chemical precipitation are prepared in situ with substrate preparation or by subsequent preparation. In high temperatures or high 
acid concentrations, the cellulose may be hydrolyzed. A neutral $\mathrm{pH}$ and low temperature are desirable during particle synthesis. During hydrothermal synthesis, the cotton fibers cracked and created a flower-like $\mathrm{TiO}_{2}$ crystal on the fiber surface (Figs. 5(d)-5(f)) (Huang et al., 2015; Li et al., 2015).

\subsubsection{Polymer coating}

Cellulose and most particles contain hydroxyl groups in their surface, with high surface energy. Therefore, active materials to decrease surface energy are applied. The link between nanomaterials and surface energy decreasing agents may be chemically crosslinked or simply a physical coating. Hydroxyl groups on the surface of nanomaterials are utilized as the active side (Peng et al., 2016a). To increase the linkages between materials (polymers or particles) and a cellulose fabric or cellulose fibers, several crosslinking agents, including Kymene $557 \mathrm{H}$, which contain carboxyl groups (Feng et al., 2015), and epichlorohydrin (Peng et al., 2016a), were used. Otherwise, active materials, such as epoxidized soybean oil (ESO), also act as an adhesive between cellulose and $\mathrm{ZnO}$ (Cheng et al., 2017c, 2018b). Chemical crosslinking increases the stability of the surface hydrophobicity. The necklace-like $\mathrm{CNC} / \mathrm{SiO}_{2}$ (Huang et al., 2019a) shows stronger adhesive properties and a more robust Cassie-Bexter's state compared to CNF only (Huang et al., 2016).

Polystyrene (PS) (Wang et al., 2010; Zhang et al., 2013), Poly(vinylidene fluoride) (PVDF), Poly(dimethylsiloxane) (PDMS) (Han et al., 2018), poly(aniline), $1 \mathrm{H}, 1 \mathrm{H}, 2 \mathrm{H}, 2 \mathrm{H}-$ perfluoro-octyltriethoxysilane (Zhou et al., 2013; Huang et al., 2019a) and trichloro (Octadecyl) silane (OTS) and (pentaflurophenyl)triethoxy silane (FAS) (Panda et al., 2018), stearic acid (Wang et al., 2021a) were applied to turn the surface from hydrophilic to hydrophobic. Polymers with fluorine atoms generally had low surface energy, therefore, producing a surface with superhydrophobic properties. However, a polymer containing fluorine is not desirable due to medical concerns (He et al., 2016; Zhang et al., 2020a). Non-synthetic hydrocarbon, including stearic acid, are also used to produce hydrophobic surfaces (Cheng et al., 2017c). Yue et al. (2018b) reported that esterification between hydroxyl groups of a solid roughness enhancer and ethanol effectively creates a superhydrophobic surface. The method of polymer coating varies from vapor deposition, dip coating to in situ polymerization (Zhang et al., 2020a). Combining the nanoparticles' roughness and the polymer's hydrophobic properties is key to producing a superhydrophobic surface.

The dip-drying repetition process increases the contact angle and stability of the surface to surfactant pollution. Evaluation of the contact angles for $\mathrm{SiO}_{2}$ and PDMS shows that the surface becomes relatively resistant to the surfactant impact even after repeating the dip-drying process 10 times. Higher dip-drying will increase the deposition of coating particles. The difference in contact angle before and after impact decreased from $\sim 20^{\circ}$ for 10 dip-drying repetitions to $\sim 2^{\circ}$ for 3 dip-drying repetitions (Han et al., 2018). Woven cotton coated with silica nanoparticles with an average diameter ranging from 7 to $40 \mathrm{~nm}$ and PDMS resin was capable of tolerating a hydrostatic head pressure of $2.56 \mathrm{kPa}$ before leaking (Zahid et al., 2017). The surface coated with $1 \mathrm{H}, 1 \mathrm{H}, 2 \mathrm{H}, 2 \mathrm{H}-$ perfluorooctyltriethoxysilane showed superhydrophobicity with a water contact angle varying between $142^{\circ}$ to $162^{\circ}$, depending on the reaction temperature and time of $\mathrm{TiO}_{2}$ ( $\mathrm{Li}$ et al., 2015). The coated fabric also demonstrated high laundering durability until five cycles. However, even surfaces with a high contact angle indicating relatively strong superhydrophobicity showed various sliding angles. The sliding angle decreased significantly to only $10^{\circ}$, and the adhesion strength remained at only $7 \mu \mathrm{N}$ after a $20 \mathrm{~h}$ reaction time. This fact suggests a transition from Wenzel's to Cassie's state, as shown in Fig. 1(d).

\subsection{Performance evaluation}

The performance of a superhydrophobic membrane is evaluated by filtration performance and material performance (Fig. 6(a)). Filtration performance measures flowrate, separation efficiency, and breakthrough pressure. Material performance measures adhesiveness, physical strength, and contact angle. Both filtration performance and material performance can be conducted under harsh conditions. The membrane is evaluated at least based on its oil and water contact angle, separation efficiency, and flow rate. Porous superhydrophobic surfaces will keep the air in their pores if immersed in water. Mirror-like observation by simply immersing the sample in water is used to confirm the existence of trapped air in the porous surface (Fig. 6(b)) (Zhou et al., 2013; Han et al., 2016). The sample will show a silver appearance underwater. High water contact angles $\left(>150^{\circ}\right)$ and oil penetration as fast as possible are desirable. Figure 6(c) shows the separation process of superhydrophobic membranes. A photograph of polar liquid droplets on a superhydrophobic surface is shown in Fig. 6(d). Scanning electron microscopy (SEM) was applied to observe the surface morphology. Either Fourier transfer infrared (FTIR) or X-ray photoelectron spectroscopy (XPS) can be used to confirm the bonding between materials in the surface ( $\mathrm{Li}$ et al., 2019c). Quantitatively, TG-DTA or dry matter content evaluates separation efficiency (Peng et al., 2016a). Flowrate depends on the performance of the membrane and oil viscosity. Higher viscosity generates lower flowrate (Cheng et al., 2017c). If the flow rate is very high, even only by gravitational force, the flowrate measurement is not necessary. However, if the flow rate is relatively low, it can be measured by simply weighing the filtrate over time divided by the membrane's surface area. 

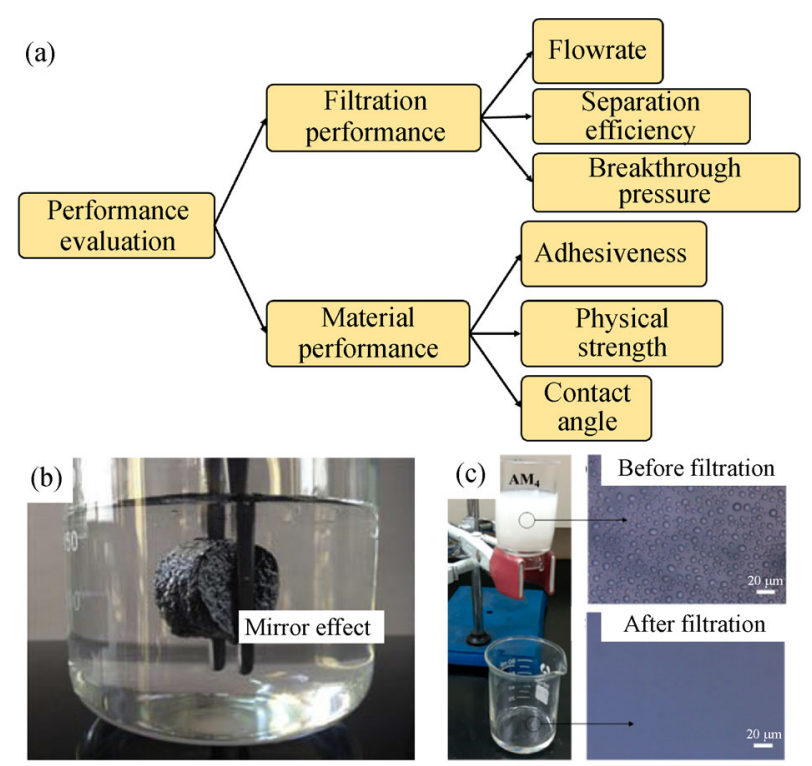

(d) Droplets of different liquids on coated cotton

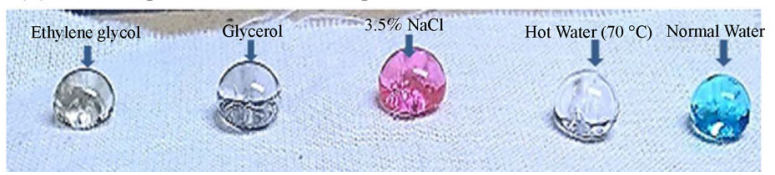

Fig. 6 (a) Diagram of performance evaluation of a superhydrophobic membrane. (b) Mirror effect of the superhydrophobic surface shows a silver-like appearance due to the air droplet in the surface void. (c) Droplet of several polar liquids. (d) Filtration process of the superhydrophobic membrane, before filtration shows droplet while after filtration shows no droplet. (b) Reproduced with permission. (Han et al., 2016) Copyright 2018, Elsevier. (c) Reproduced with permission. (Zhou et al., 2018) Copyright 2018, American Chemical Society. (d) Reproduced with permission. (Panda et al., 2018) Copyright 2016, Elsevier.

The stability and durability of a membrane are evaluated using several criteria. Immersion in solutions with extremely high or low $\mathrm{pH}$ (1-2 for strongly acidic and 12-13 for strongly alkaline solutions) or a high salt concentration $(\mathrm{NaCl} 3.5 \mathrm{wt} \%)$ for $1-72 \mathrm{~h}$ evaluates the durability of the membrane under harsh conditions (Wang et al., 2016a). Adding a drop of a surfactant solution (4.1 mM SDS) (Zhou et al., 2013; Han et al., 2018) or heating at a temperature between $60^{\circ} \mathrm{C}$ and $120^{\circ} \mathrm{C}$ for $72 \mathrm{~h}$ (Zhou et al., 2013) evaluates the membrane surface's heat resistance. The dropping test using a surfactant aims to examine the influence of pollutants on the surface. Meanwhile, with water it aims to determine the possibility of transitioning from the Cassie-Baxter to the Wenzel state (Huang et al., 2019a). Stable surfaces only require drying to eliminate the effects of water dropping and recover their initial properties.

The detachment of the pollution evaluates a superhydrophobic membrane's self-cleaning ability by dissolving it in water. Methyl orange powder was sprinkled on the membrane surface, and then water was dropped on the surface. If the surface has a self-cleaning ability, all of the powder will be detached and carried away by the water leaving a clean surface (Huang et al., 2015). As a result, the surface's hydrophobicity decreased when the water molecules penetrated the surface and became attached to the mesostructure. Thus, the surface's affinity for sustainability was evaluated by subjecting it to high humidity (95\% RH) for $72 \mathrm{~h}$ (Zhou et al., 2013) or immersing it in water for up to 7 days (Cheng et al., 2017c).

Various abrasion tests conducted with another cotton fabric, sandpaper for 30-600 scratch cycles at 50-260 g of weight applied (Zhou et al., 2013; Huang et al., 2015, 2019a; Wang et al., 2020b), finger wipes and knife scratches (Huang et al., 2019a), ultrasonication for $2 \mathrm{~h}$, and laundering 30 times (Yang et al., 2019b) were conducted to evaluate the affinity of coated particles after physical damage. The resistance of the surface to UV irradiation was evaluated by exposure to UV light ( $\ddot{\mathrm{e}}=$ $254 \mathrm{~nm}$ ) at a distance of $10 \mathrm{~cm}$ for 1-6 days (Wang et al., 2016a; Huang et al., 2019a). The material's biodegradability was evaluated for environmental concerns by measuring weight loss over time due to hydrolytic degradation in a phosphate buffer solution $(\mathrm{pH} 7.4$, $37^{\circ} \mathrm{C}$ ) (Cheng et al., 2017c). More than ten filtration cycles using the same filter were used to assess the membrane's continuity in separating the oil/water mixture/ emulsion. The aerogel was recovered after each separation process by washing it with an organic solvent such as ethanol (Wang et al., 2016a; Zhou et al., 2018) or a combination of alcohol and water (Zhou et al., 2013).

The summary of several superhydrophobic membranes 
is presented in Table 2. Several membranes are without roughness enhancer because the structure of supporting materials is rough enough. The non-cellulose based membranes are also without polymer coating due to nonpolar inherent properties of supporting materials.

\section{Superoleophobic surfaces}

\subsection{Principles of superoleophobic membranes}

Cellulose with abundant hydroxyl groups quickly absorbs water molecules into its structure. The simulation study shows that the hydrophilic functional groups are, in decreasing order, mixed-charged zwitterionic, hydroxyl, ethanolamine, oligo(ethylene glycol), amide, methyl groups (Cheng et al., 2017a). The hydrophilicity of cellulose surfaces provides underwater oleophobicity. In nature, fish scales (Waghmare et al., 2014; Halim et al., 2020a), clamshells (Liu et al., 2012), and mussels (Wang et al., 2015d) show underwater oleophobicity. Fish keep their skin surface clean even when living in harsh environments. The mucus layer of the fish skin is created by absorbing water by protein to produce skin moieties. This layer repels organic materials, including oil sticking to the fish's skin. The characteristics of fish skin inspired the production of a membrane that can repel organic materials, including oil and bacteria. This feature has the potential to create a self-cleaning membrane and immune to the organic fouling (Wu et al., 2018; Guo et al., 2019; Yi et al., 2019). The mucus layer in fish skin increases the oleophobicity, as indicated by the contact angle (Figs. 7(a)-7(c)). Fish scales also consist of micropapillae to increase their roughness, as shown in Fig. 7(d) (Liu et al., 2009; Waghmare et al., 2014). The composite electrospun cellulose with graphene oxide showed a corrugated structure similar to the micropapillae of a fish scale (Ao et al., 2017). In membrane application, the term mucus layer may refer to hydrogel (Rohrbach et al., 2014; Fan et al., 2015; Ao et al., 2018; Xie et al., 2020) or a liquid infused surface (Halim et al., 2020a; Ashrafi et al., 2021). Many hydrophilic surfaces lose their hydrophilicity and self-cleaning function due to a defect that occurs once a hydrophobic liquid comes into contact with the surface. Cellulose nanofiber demonstrated high stability even after oil defects (Huang and Wang, 2017).

Figure 7(e) shows the mechanism of a superoleophobic membrane. First small droplets collide with each other or with large droplets to form even larger droplets. Sequentially, the droplets will be repelled once they touch the membrane surface. Therefore, superoleophobic membranes are suited to oil-in-water mixtures or emulsions.

\subsection{Preparation of superolephobic membranes}

Superoleophobic membranes generally require prewetting before use. However, in some non-cellulose membranes no prewetting was reported to be necessary (Peng et al., 2020). Different prewetting conditions produced different surface properties (Fan et al., 2018). However, some membranes maintained good hydrophilicity even in oil environments (Wang et al., 2015b). The prewetting process is necessary to determine the interaction between water molecules and membrane surfaces. Due to cellulose's natural oleophobic properties, cellulose requires less modification of its surface compared to superoleophobic and Janus membranes. The primary modifications include increasing surface roughness, crosslinking between cellulose molecules, cellulose and nanomaterials, or cellulose with supporting materials, and decreasing the membrane's pore size. Particles that increase the nanostructure roughness of the surface, such as $\mathrm{BaSO}_{4}$ particles, were precipitated in the surface of the cellulose fiber (Yang et al., 2020).

The cellulose could act as either a supporting material or an active material (Fig. 8(a)). For cellulose as a supporting material, the fabrication and preparation are relatively similar to superhydrophobic membranes. Cellulose as an active material mainly occurs in the form of a hydrogel. Paper-like (Rohrbach et al., 2014), aerogel (He et al., 2016; Fu et al., 2020) and sponge-like (Wang et al., 2015b; Halim et al., 2019), woven (Dai et al., 2019), and non-woven membranes (Almeida et al., 2020) were reported. Non-cellulose supporting materials provide relatively higher physical strength compared to cellulose filter paper or sponges. A wide range of mesh from nylon (Lu et al., 2014; Cheng et al., 2017b) to metal mesh (Ao et al., 2018; Xie et al., 2020) were reported. However, all biodegradable organic materials are preferred. A 3D printing of cellulose acetate mesh followed by cellulose regeneration using an ethanol/ $\mathrm{NaOH}$ solution was reported by Koh et al. (Koh et al., 2019). The pore size and structure are easily engineered.

Moreover, production using the $2 \mathrm{D}$ printing of $\mathrm{CNC}$ on a non-woven cellulose acetate makes the pattern, size, and $\mathrm{CNC}$ ratio easy to control in order to optimize oil retention (Almeida et al., 2020). Figure 8(b) shows an SEM image of a superoleophobic membrane for cellulose as an active material. Here, cellulose hydrogel coats a metal mesh. Figure $8(\mathrm{c})$ shows cellulose acting as both a supporting material and as an active material. Figure 8(d) shows cellulose as a supporting material with coated particles, and Fig. 8(e) shows a cellulose sponge.

The quantity of cellulose deposited to the supporting materials influences the hydrophilicity and oleophobicity of the membrane. The nylon's contact angle changed from 88.7 without a CNF usage to 175.9 with a CNF usage of $0.73 \mathrm{~g} / \mathrm{m}^{2}$, due to the cellulose area coverage. After all supporting material is covered, the contact angle is independent of the CNF concentration (Cheng et al., 2017b). The chitosan forms a self-assembly structure that produces a micrometer dot on the surface during 


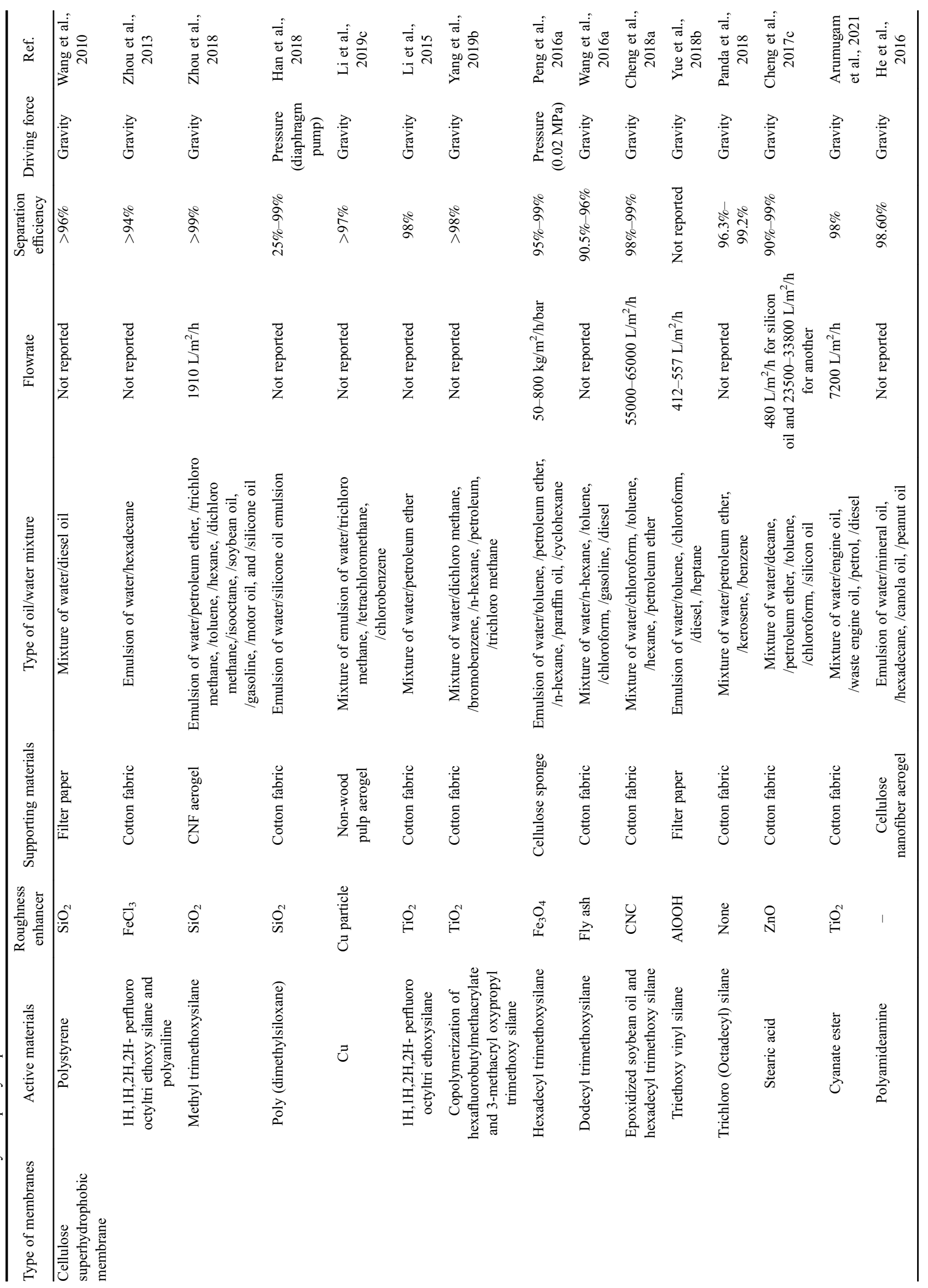




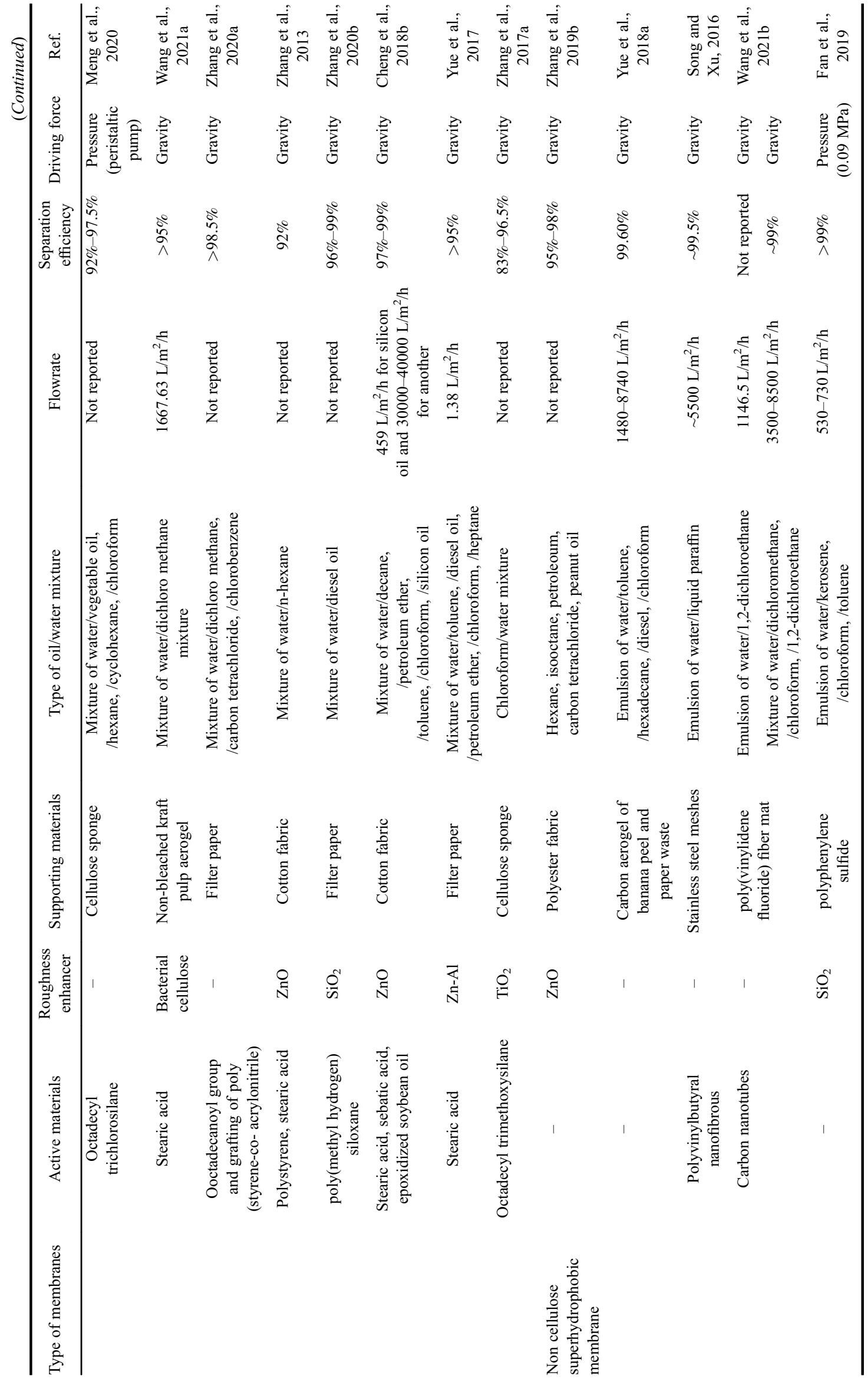


(a)

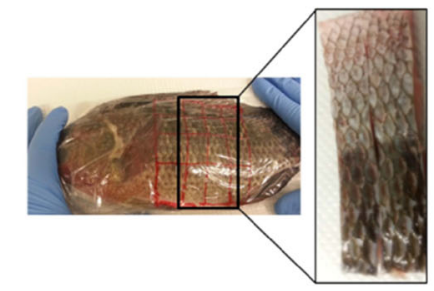

(b)
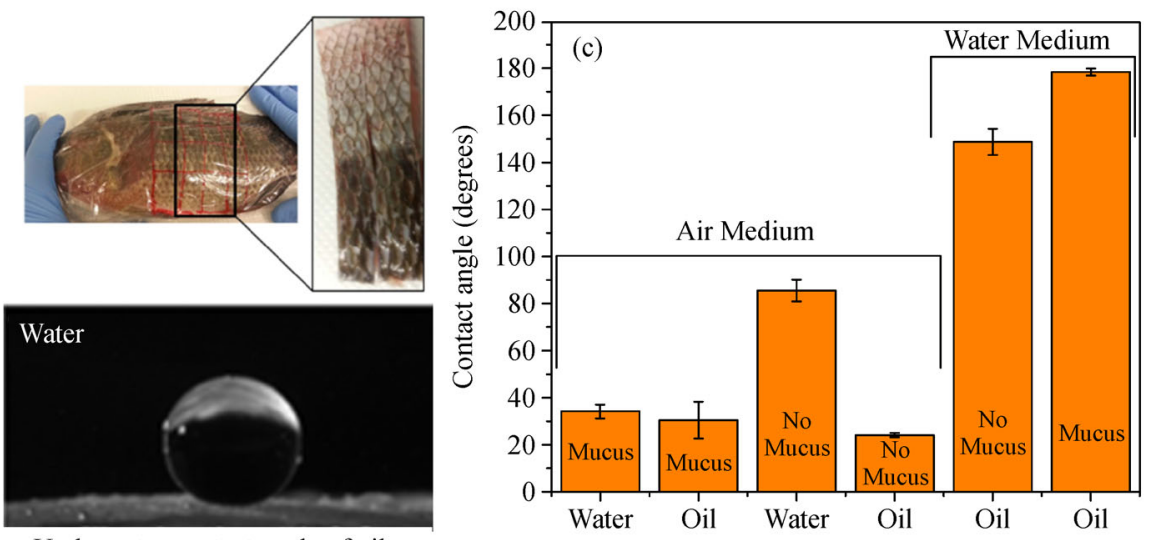

Underwater contact angle of oil on fish skin surface

(d)

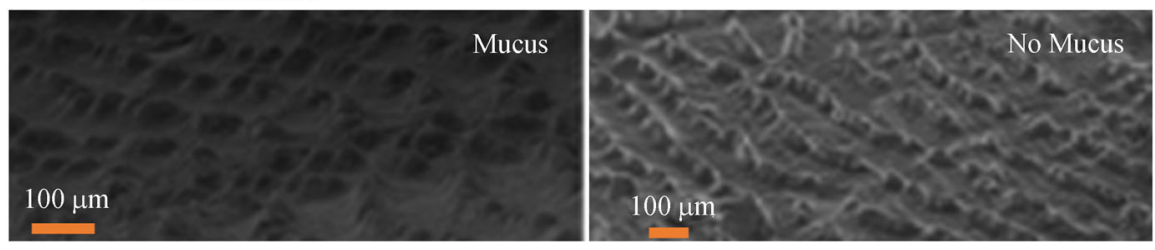

(e)

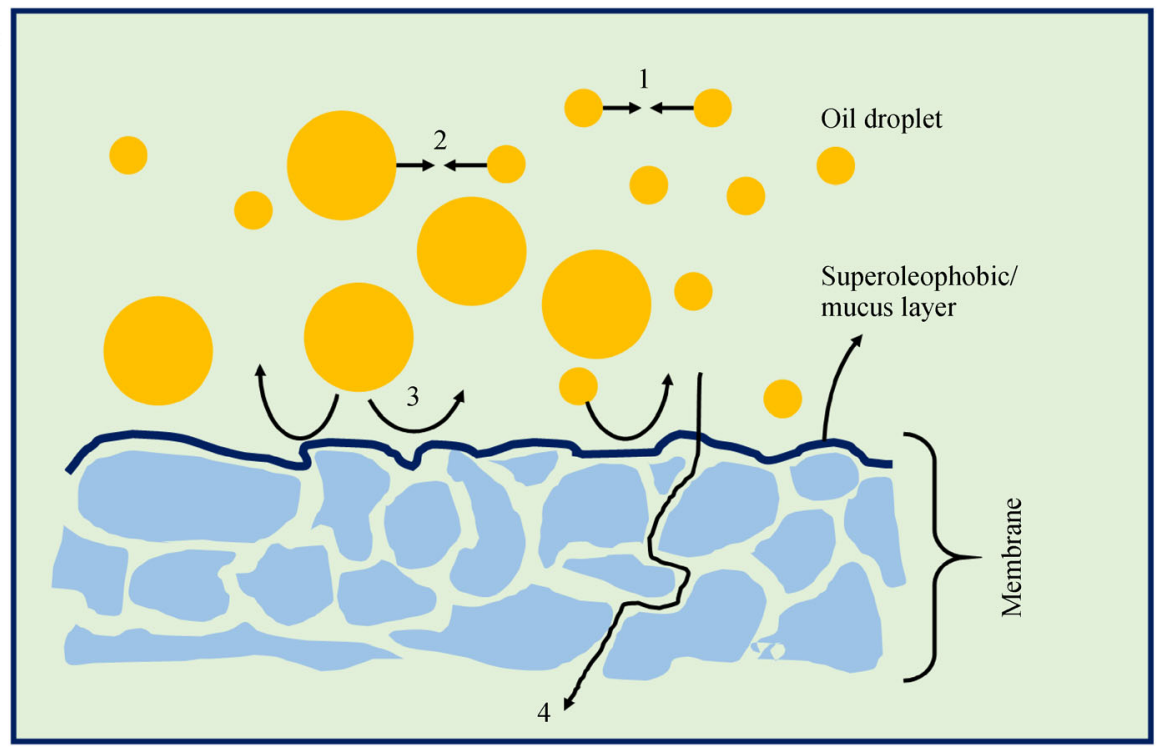

Fig. 7 (a) Photo image of fish skin. (b) SEM image of mucus, and no mucus fish skin surface. (c) A drop of oil on the surface of fish skin shows a superoleophobic contact angle. (d) The contact angle value of fish skin under air and underwater with and without mucus. (e) Separation mechanism of superoleophobic membrane. Small droplets collide with each other (1). Small droplets collide with large droplets (2). Oil droplet is rejected (3) and water passes through the membrane (4). (a-d) Reproduced with permission. (Waghmare et al., 2014) Copyright 2014, Springer Nature.

composition with chitosan. A decrease in XRD intensity indicates decreasing crystallinity and hydrogen bonding. Exposing more hydroxyl groups to the surface is verified by increasing the OH peak by FTIR (Peng et al., 2016b).

Roughness to form a water cushion, repellency of polar liquids, and the membrane surface's zeta potential enhance its underwater oleophobicity. Underwater, the oil droplets are slightly negative (Roger and Cabane, 2012). Negative zeta potential of the membrane surface will enhance its oleophobicity. The TEMPO-oxidized cellulose showed a high underwater oil contact angle compared to the Mechanical CNF due to higher negative zeta potential (Halim et al., 2019). The surface charge of the membrane interacts with the surfactant and determines the separation efficiency. Due to the charge of the membrane being affected by the environment's $\mathrm{pH}$, feed plays a key role. Anionic surfactants, such as sodium dodecyl benzyl sulfonate (SDBS), were the least stable due to their higher 



Fig. 8 (a) Classification diagram of cellulose in superoleophobic membranes. Scanning electron microscopy (SEM) image of cellulose hydrogel coated mesh (b), cellulose hydrogel coated filter paper (c), filter paper with coated particle (d), and cellulose sponge (e). (b) Reproduced with permission. (Ao et al., 2018) Copyright 2018, Elsevier. (c) Reproduced with permission. (Rohrbach et al., 2014) Copyright 2014, The Royal Society of Chemistry. (d) Reproduced with permission. (Yang et al., 2020) Copyright 2020, Springer. (e) Reproduced with permission (Wang et al., 2015b). Copyright 2015, The Royal Society of Chemistry.

surface tension and positive zeta potential. Cationic surfactants, including hexadecyltrimethylammonium bromide (CTAB), and neural surfactants, such as polysorbate 80 (Tween 80), demonstrated higher stability. By controlling the $\mathrm{pH}$, the membrane's zeta potential can be adjusted to positive or negative to selectively increase the filtration performance of a particular surfactant (Kim et al., 2019).

Similar to the hydrophobic membranes, electrospinning was also applied to the oleophobic membranes followed by freeze-drying to fabricate aerogel. A thin layer of cellulose membranes was reported on different sources of cellulose nanofiber (Mautner et al., 2014), cellulose nanocrystal (Cheng et al., 2017b), and cellulose solution in a urea/ $\mathrm{NaOH}$ system (Zhou et al., 2014; Peng et al., 2016b). During heating, crystallization occurred in the cellulose solution, expelling the cellulose to form a nanosheet. The nanomembrane shows a transparent and chiral nematic substance, due to the cholesteric self-assembly of CNC (Cheng et al., 2017b). The nanopaper of CNF fabricated by paper making is affected by the role of zeta potential in coagulation and formation (Mautner et al., 2014). The thickness of the paper was a linear function of the concentration of the quantity of cellulose suspension. At the same time, thickness reversely affects the flowrate almost in linear function (Zhou et al., 2014; Cheng et al., 2017b). Cellulose sponge was fabricated by routine dissolution and regeneration with the template of $\mathrm{Na}_{3} \mathrm{PO}_{4}$ (Halim et al., 2019, 2020b) or $\mathrm{Na}_{2} \mathrm{SO}_{4} \cdot 10 \mathrm{H}_{2} \mathrm{O}$
(Wang et al., 2015b). Reinforced fiber can be added to increase mechanical strength. Sandwiching of nanoporous layers and a microporous layer was also reported (Wang et al., 2015b).

Additional polymers increase oleophobicity by increasing roughness. PEI modified CNF aerogel followed by grafting with PDMAEMA increases the surface area from 4.30 to $12.72 \mathrm{~m}^{2} / \mathrm{g}$ due to the brushiness of the polymer increasing the roughness of the surface (Li et al., 2019b). Coating and additives also produce additional features, including switchability and absorption ability. Switchable oleophobicity of cellulose aerogel can also be tuned by nanoparticles $\mathrm{TiO}_{2}$ using $\mathrm{UV}$ radiation, as explained in the previous section (Kettunen et al., 2011). Another method is generating $\mathrm{CO}_{2}$ gas-sensitive switchable surfaces by coating with PDMAEMA (Li et al., 2019b). PDMAEMA is in the deprotonated state in the absence of $\mathrm{CO}_{2}$, while $\mathrm{CO}_{2}$ exposure protonates the brush polymer and acquires a positive charge. The flux of oil (hydrophobic state) is four times higher than the water flux (oleophobic state) due to effective porosity reduction; however, the separation efficiency is almost one-ninth of the oleophobic state. PDMAEMA reduces the porosity by bonding with $\mathrm{H}_{2} \mathrm{O}$. As cellulose has an abundance of hydroxyl group, the membrane is also used as a dye absorbent (methylene blue, rhodamine B, and gentian violet) (Zhu et al., 2017; Huang et al., 2019b). By composting with graphene oxide, the dye removal efficiency is up to $97 \%$ with flux from 170 to 
$300 \mathrm{~L} / \mathrm{m}^{2} / \mathrm{h}$ (Zhu et al., 2017). The cationic dye is absorbed by an electrostatic interaction between the dye and oxygen group of graphene oxide (GO). Therefore, a desorption agent, for example $\mathrm{HCl}$, is used to renew the membrane. A composite is also necessary to elevate the efficacy of the membrane's performance. The CNF membrane without graphene oxide was incapable of separating an oil-water mixture. The graphene oxide affected the microstructure and wettability of the membrane (Ao et al., 2017).

For the coating of active materials, the cellulose solution was coated onto the supporting materials followed by drying. The catalyst performed chemical crosslinking to increase the adhesion between cellulose and the supporting material or nanoparticles (Rohrbach et al., 2014; Xu et al., 2019). Types of crosslink and catalyst materials included citric acid and glutaraldehyde (Rohrbach et al., 2014), guar gum and $\mathrm{NaIO}_{4}$ (Dai et al., 2019). Epichlorohydrin (Huang et al., 2019b) and polyamide amine-epichlorohydrin (He et al., 2016) were also used as crosslinking materials. Crosslinks typically used are esterification between aldehyde, and alcohol groups between coated materials, coated materials and cellulose, or between cellulose. The polyamide amine-epichlorohydrin waterinsoluble prevents detachment of fibers during rewetting (He et al., 2016). The concentration of guar gum and $\mathrm{NaIO}_{4}$ plays a significant role in the success of a reaction. Under $1 \mathrm{wt} \%$ of GG, no reaction happens for $\leqslant 0.0022$ and $\geqslant 2.2 \mathrm{~g} \mathrm{NaIO}_{4} / \mathrm{g}$ GG. Under $0.022 \mathrm{~g} \mathrm{NaIO}_{4} / \mathrm{g} \mathrm{GG}$, no reaction happens for $0.5 \mathrm{wt} \%$ and $1 \mathrm{wt} \%$ GG. Crosslinking only by annealing at $150^{\circ} \mathrm{C}$ was reported by Almeida et al. (Almeida et al., 2020). The annealing process changes the color of $\mathrm{CNC}$ to be darker. Crosslinking agents provide more crosslinking density between materials, which enhances the separation efficiency and improves physical strength (Huang et al., 2019b).

\subsection{Performance of superoleophobic membranes}

The performance evaluation criteria for superoleophobic membranes are similar with those for superhydrophobic membranes except for the evaluation of performance conditions. For instance, instead of using water as a contact angle measurement in the air, the superoleophobic membrane uses oil underwater to evaluate the contact angle. This underwater contact angle of the surface is the first characteristic to be investigated (Fig. 9(a)). Otherwise, the strength of the membrane is evaluated by mechanical compression (Zhu et al., 2017; Halim et al., 2019) or tensile strength (Ahmed et al., 2014). For mechanical compression, a compression strain of up to $85 \%$ was reported (Zhu et al., 2017; Halim et al., 2019). For tensile evaluation, the stretching rate is $1 \mathrm{~mm} / \mathrm{min}$, and the stressstrain curve was recorded (Ahmed et al., 2014). A polymer coating of polyvinyl alcohol increases filter paper's physical strength by providing robust hydrogen bonding and protecting the acidic or alkaline condition (Fan et al.,
2015). Cellulose coating on a PVDF-HFP nanofiber membrane also increases the mechanical tensile strength from 5.5 $\mathrm{MPa}$ to $8.6 \mathrm{MPa}$ with the elastic modulus increasing from $17.4 \mathrm{MPa}$ to $54 \mathrm{MPa}$ with $15 \%$ cellulose content (Ahmed et al., 2014). Coating with paraffin wax shows an improvement in elastic modulus from 521.3 to $1.2 \mathrm{GPa}$. In contrast, the elongation break decreases from $9.4 \%$ to $4.1 \%$. The improvement is assumed to be due to the physical crosslink between fiber and paraffin wax. However, coating with PDMS- $b$-PEO does not demonstrate any improvement in mechanical strength (Paul et al., 2016).

PDMAEMA grafting increases the compression stress from $30 \mathrm{kPa}$ for PEI modified CNF aerogel to $61 \mathrm{kPa}$ when compressed to $50 \%$ of its thickness due to an increase in density from $37.17 \mathrm{mg} / \mathrm{cm}^{3}$ to $57.58 \mathrm{mg} / \mathrm{m}^{3}$ ( $\mathrm{Li}$ et al., $2019 \mathrm{~b}$ ). The compression strength of cellulose hydrogel 7.9 to $14.45 \mathrm{MPa}$ depends on the regeneration conditions. Low temperature slows the cellulose regeneration producing more compact and homogenous stacking of the cellulose chain. Poor solvents also cause an irregular and bulky structure (Xie et al., 2020).

Higher cellulose content decreases the tensile strength due to high content; the cellulose is very thick. During drying, shrinking can take place and cracks appear. With a lower content, the cellulose glues the fiber, increasing the stiffness of the membrane. $\mathrm{H}^{+}$in the acidic condition decreases the mechanical strength by decomposition of the cellulose polymer. Ion $\mathrm{H}^{+}$and $\mathrm{OH}^{-}$also break the hydrogen bonding of cellulose. Underwater, the annealed CNC coating captures the microdroplets. The microdroplets coalesce with each other to form a larger oil droplet, which is removed from the surface (Almeida et al., 2020). Polymer coating of polydopamine acts as a glue between cellulose and $\mathrm{BaSO}_{4}$ particles (Yang et al., 2020).

Other parameters that affected separation performance include the pore size of the membrane, tortuosity, and breakthrough pressure. These three parameters correlated with each other. The membrane requires a slightly lower pore diameter than the droplet diameter to prevent the oil droplet from passing through the membrane or entering the membrane's pores (Schutzius et al., 2017). The coating also decreases the pore size, providing not only surface repellency but also a size-based barrier. By decreasing the pore size, the membrane's performance enhances from only separating oil-water mixtures to separating oil-water emulsions (Wang et al., 2017a). During filtration, the repellency pushes against the applied pressure. The maximum pressure before the droplet penetrates the membrane is called the breakthrough pressure, expressed as Eq. (8):

$$
P=-\frac{2 \gamma_{O W} \cos \theta}{d},
$$

wherein $P, \gamma_{O W}, d$, and $\theta$ are the breakthrough pressure, interfacial surface tension between oil and water, the 
diameter of a pore, and OCA against water, respectively. As filtration force is limited to gravity, $P$ is equivalent to gravitational pressure $P_{g}=\rho g h$, where $\rho$ is the density of oil, $g$ is the gravitational acceleration $\left(9.81 \mathrm{~m} / \mathrm{s}^{2}\right)$, and $h$ is the height of the oil-water mixture in the filter holder during the experiment (Fig. 9(b)). From the equation, the maximum diameter of the filter pore can be calculated. The typical surfactant-free oil droplet emulsion is larger than 20 $\mu \mathrm{m}$; therefore, a membrane with lower pore size of $20 \mu \mathrm{m}$ will block the oil and the separation efficiency will depend on the membrane pore size (Ahmed et al., 2014). For instance, 3D printed cellulose using hexadecane as an oil model showed that at a diameter lower than $280 \mu \mathrm{m}$, the separation efficiency was higher than $91 \%$ but decreased to $74 \%$ at a diameter of $375 \mu \mathrm{m}$ and $35 \%$ at a diameter of $545 \mu \mathrm{m}$ (Koh et al., 2019). A cellulose nanofiber membrane with a pore size of approximately $21.6 \mathrm{~nm}$ was reported to separate a surfactant stabilized oil emulsion with an oil diameter of $119 \mathrm{~nm}$ (Zhuang et al., 2020). However, the pore size is not the only parameter to determine the separation efficiency. Tortuosity and flow dynamics that initiating the oil droplet collision increase the separation efficiency. However, even the viscosity of the oil determines the flow dynamics; viscosity shows no correlation with separation efficiency, as shown by xylene with a viscosity of $0.6 \mathrm{cP}$, which has a separation efficiency of only $94 \%$. However, both PDMS with a high viscosity of $97 \mathrm{cP}$, and cyclohexane with a low viscosity of $1 \mathrm{cP}$ show a high separation efficiency of $99 \%$ (Koh et al., 2019).

Large pore size increases flux; however, the separation efficiency and breakthrough pressure decreases significantly. The oil intrusion evaluation observes the membrane's maximum static pressure to retain oil (Fig. 9(b)). The electrospinning cellulose composited with graphene oxide had a pressure of $2.56 \mathrm{kPa}$ for a membrane thickness of $\sim 100 \mu \mathrm{m}$ (Ao et al., 2017) and $1.94 \mathrm{kPa}$ for cellulose hydrogel coated mesh (Ao et al., 2018). The colander from cellulose-coated nylon mesh also showed a high breakthrough pressure of more than $1.26 \mathrm{kPa}$ (Lu et al., 2014). The breakthrough pressure for cellulose coated with polydopamine and $\mathrm{BaSO}_{4}$ was $1.25 \mathrm{kPa}$ (Yang et al., 2020).

Not all coating methods decrease the porosity of the membrane. Paraffin wax decreases the porosity from 53\% to $43 \%$. However, PDMS- $b$-PEO does not have a significant effect on porosity (only decreasing up to $53.5 \%$ ). In contrast, a combination of paraffin wax and PDMS- $b$-PEO decreases the porosity to $41 \%$ (Paul et al., 2016). The oil coalesces during separation also increasing the separation efficiency by increasing the diameter of the oil droplets. With a flow velocity of $6.7 \times 10^{-4} \mathrm{~m} / \mathrm{s}$, the minimum diameter for oil droplet coalescences and upward flow is $89 \mu \mathrm{m}$ (He et al., 2016). Nanoporous membranes are fabricated by freeze-drying without a forming agent, whereas microporous membranes are fabricated with a forming agent. Microporous membranes are only capable of separating oil-water mixtures, whereas nanoporous membranes are capable of separating oil-water emulsions (Wang et al., 2015b). Nanoporous membranes can be measured by the molecular cut-off of polyethylene oxide for several molecular weights of $100 \mathrm{kDa}, 300 \mathrm{kDa}$, and $600 \mathrm{kDa}$ (Cheng et al., 2017b). There is a trade-off between separation efficiency and flow rate. Increasing separation efficiency by decreasing pore size worsens the flow rate. In the same manner, a higher oil droplet diameter also decreases the flow rate by blocking the membrane surface. The flow rate decreases from 9.16 to $1.25 \mathrm{~L} / \mathrm{m}^{2} / \mathrm{h} /$ bar by increasing the oil droplet diameter from 119 to 152 $\mathrm{nm}$ (Zhuang et al., 2020). Freeze-drying cellulose aerogel at a concentration of $0.0197 \mathrm{~g} / \mathrm{mL}$ has a deionized flow rate of $27022 \mathrm{~L} / \mathrm{m}^{2} / \mathrm{h}$ with oil rejection being $56.3 \%$, while cellulose aerogel at a concentration of $0.0337 \mathrm{~g} / \mathrm{mL}$ has a deionized flow rate of $2405 \mathrm{~L} / \mathrm{m}^{2} / \mathrm{h}$, and oil rejection of 98.6\% (He et al., 2016).

The oleophobic membranes' performance and stability were evaluated based on their cleaning ability, water contact angle, ability to withstand harsh conditions, and physical damage to the surface. Stability in chemically harsh or corrosive conditions can be evaluated by filtration using an acid solution of 0.1-1 $\mathrm{M} \mathrm{HCl}$ (Ao et al., 2017; Cheng et al., 2017b; Yang et al., 2020), $\mathrm{pH}=1$ (Koh et al., 2019) or $0.1 \mathrm{M}$ muriatic acid ( $\mathrm{Lu}$ et al., 2014), alkaline 0.1-1 M NaOH (Lu et al., 2014; Ao et al., 2017; Cheng et al., 2017b; Yang et al., 2020) or $\mathrm{pH}=11-13$ (Dai et al., 2019; Koh et al., 2019), or high salt concentration of 0.1-1 M (Lu et al., 2014; Cheng et al., 2017b; Yang et al., 2020) or $5 \mathrm{wt} \%-10 \mathrm{wt} \% \mathrm{NaCl}$ (Peng et al., 2016b; Ao et al., 2017; Dai et al., 2019), or seawater (Koh et al., 2019). Furthermore, the membranes were exposed to harsh conditions for different durations of time. Artificial harsh condition evaluation involves the immersion of a membrane in saturated salt for $24 \mathrm{~h}$ (Ao et al., 2018), in an acidic condition of 2-8 $\mathrm{M} \mathrm{H}_{2} \mathrm{SO}_{4}$ for 10 min-30 days (Fan et al., 2015), in an alkaline condition of $\mathrm{NaOH}$ for $10 \mathrm{~min}-$ 30 days (Fan et al., 2015), and in water for 90 days $(\mathrm{Lu}$ et al., 2014). The alkaline condition was able to coalesce the oil to form a stable oil emulsion even without a surfactant due to the oil droplets being negatively charged (Koh et al., 2019).

Hydrophilicity and self-cleaning performance under oil are evaluated by measuring the water contact angle under oil (Cheng et al., 2017b) or under oil after one day of immersion (Koh et al., 2019). Separation efficiency is qualitatively evaluated using the Tyndall effect (Cheng et al., 2017b) or microscope observation (Wang et al., 2017a) (Figs. 9(c) and 9(d)). Quantitative evaluation is conducted using TGA or drying (Halim et al., 2019). Type of oily wastewater affects the separation efficiency by its wastewater content such as $\mathrm{pH}$ or oil droplet size. Yi et al. 




Fig. 9 (a) Photo image of an oil droplet on a superoleophobic surface. (b) Illustration of separation performance evaluation. $h$ is the maximum high of oil after separation was completed to measure breakthrough pressure. (c) The red line shows when a red laser beams through water containing microdroplets, while no red line appears for filtrates. (d) Before separation, the emulsion appears white in color with droplets of oil. However, after separation, the filtrate shows a clear appearance with no droplets detected. (a) and (d) Reproduced from (Wang et al., 2017a) Copyright 2017, Springer Nature. (c) Reproduced with permission. (Cheng et al., 2017b) Copyright 2017, Elsevier.

(2019) reported that commercial cutting fluid emulsion shows lower separation efficiency $(91 \%)$ than homemade oil emulsion $(96.7 \%)$.

Stability under thermocycling is evaluated through five cycles of freezing at $-18^{\circ} \mathrm{C}$ and thawing at room temperature, or by heating to $60^{\circ} \mathrm{C}$ and cooling to room temperature (Dai et al., 2019) to observe the water leaching out of irreversible phase change. Mild temperature evaluation is conducted through the use of a solution at a temperature of $10^{\circ} \mathrm{C}-80^{\circ} \mathrm{C}$ (Cheng et al., 2017b), or sonication at a power of $180 \mathrm{~W}$ for $30 \mathrm{~min}$ to evaluate the coating bonding (Zhu et al., 2017; Koh et al., 2019). Sandpaper abrasion with $100 \mathrm{~g}$ loading and adhesive tape with $100 \mathrm{~N} / \mathrm{m}$ adhesive strength was used (Huang et al., 2019b). Resistance to UV light was evaluated at a $365 \mathrm{~nm}$ wavelength (Huang et al., 2019b).

The antifouling and reusability of the membrane (recovery rates) can be observed using 10-60 cycle filtrations and evaluating the flowrate or separation efficiency during cycling. Superoleophobic membrane shows antifouling properties by maintaining high flux and separation efficiency. If the coating is in hydrogel form, the rheology measurement can be applied under a frequency of $10 \mathrm{rad} / \mathrm{s}$ and strain at $1 \%$. For clear appearance purposes, the water is dyed with methylene blue (Huang et al., 2019b), while the oil is dyed with Sudan III (Huang et al., 2019b) or red oil O (Rohrbach et al., 2014). Table 3 summaries several superoleophobic membranes. Generally, cellulose materials, either as supporting material or as active material has rough enough surface.

\section{Janus surfaces}

\subsection{Principles of Janus membranes}

Janus materials have two surfaces with different properties in reference to the two-faced Roman god, Janus. This means Janus materials have two sets of opposite properties; Hydrophobic on one side and hydrophilic on the other side. In nature, plants and creatures that have two opposite properties include Salvinia (Barthlott et al., 2010) and Namib beetles (Parker and Lawrence, 2001). The eggbeater-like fur of Salvinia plants has a hydrophobic coating on the stalk and a hydrophilic coating on the terminal of the fur. This structure stabilizes the air-water interface, especially during rippling conditions (Figs. 10(a)-10(d)). The Namib beetle has a hydrophilic side to collect water from fog and a hydrophobic side to direct the water to the beetle's mouth (Parker and Lawrence, 2001; Zhai et al., 2006) (Figs. 10(e) and 10(f)). Therefore, a Janus membrane has superhydrophilic on one side and has superhydrophobic on another side as shown in Figs. 10(g) and $10(\mathrm{~h})$.

Janus membranes have a hydrophilic surface on one side 


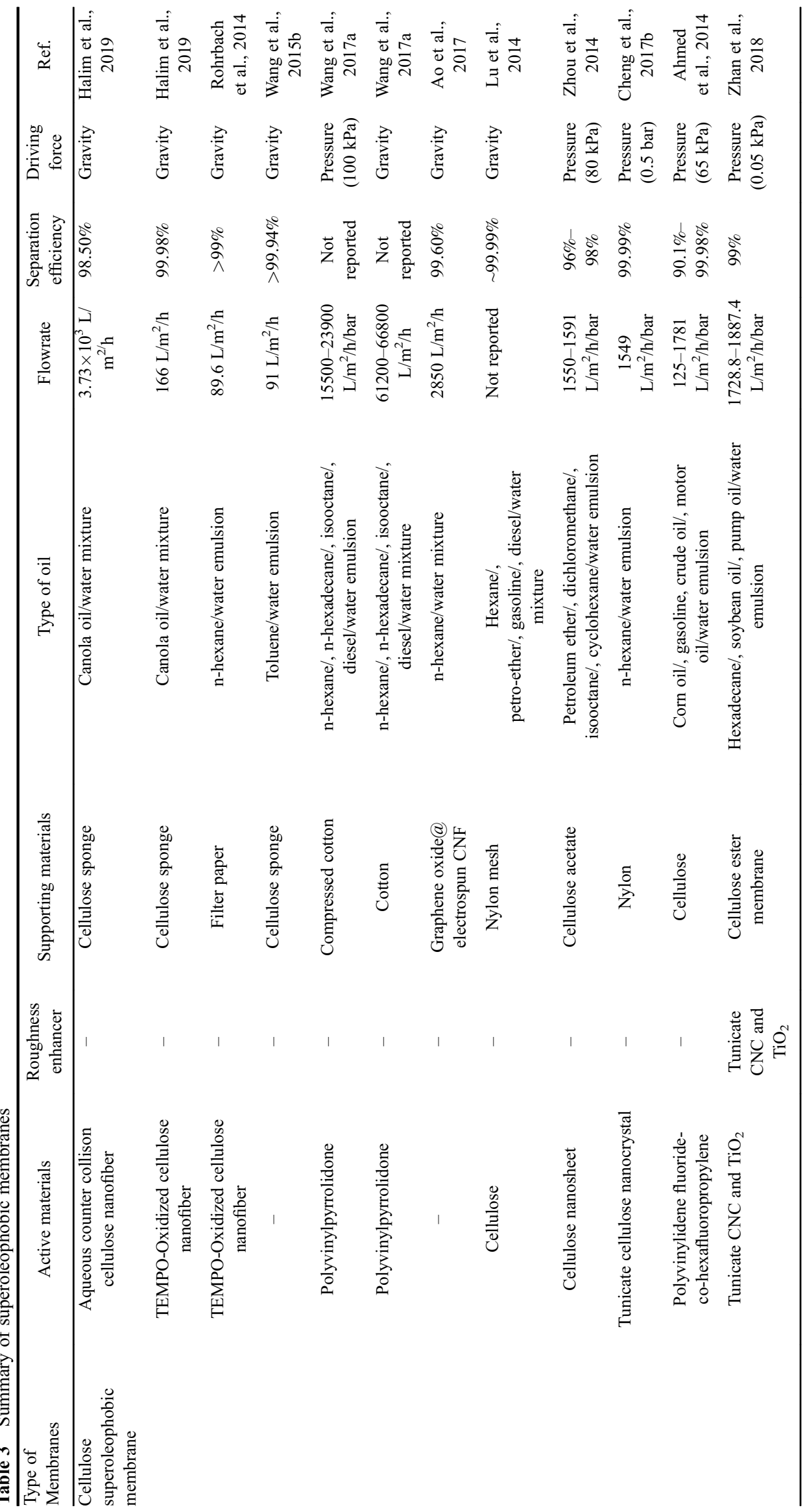




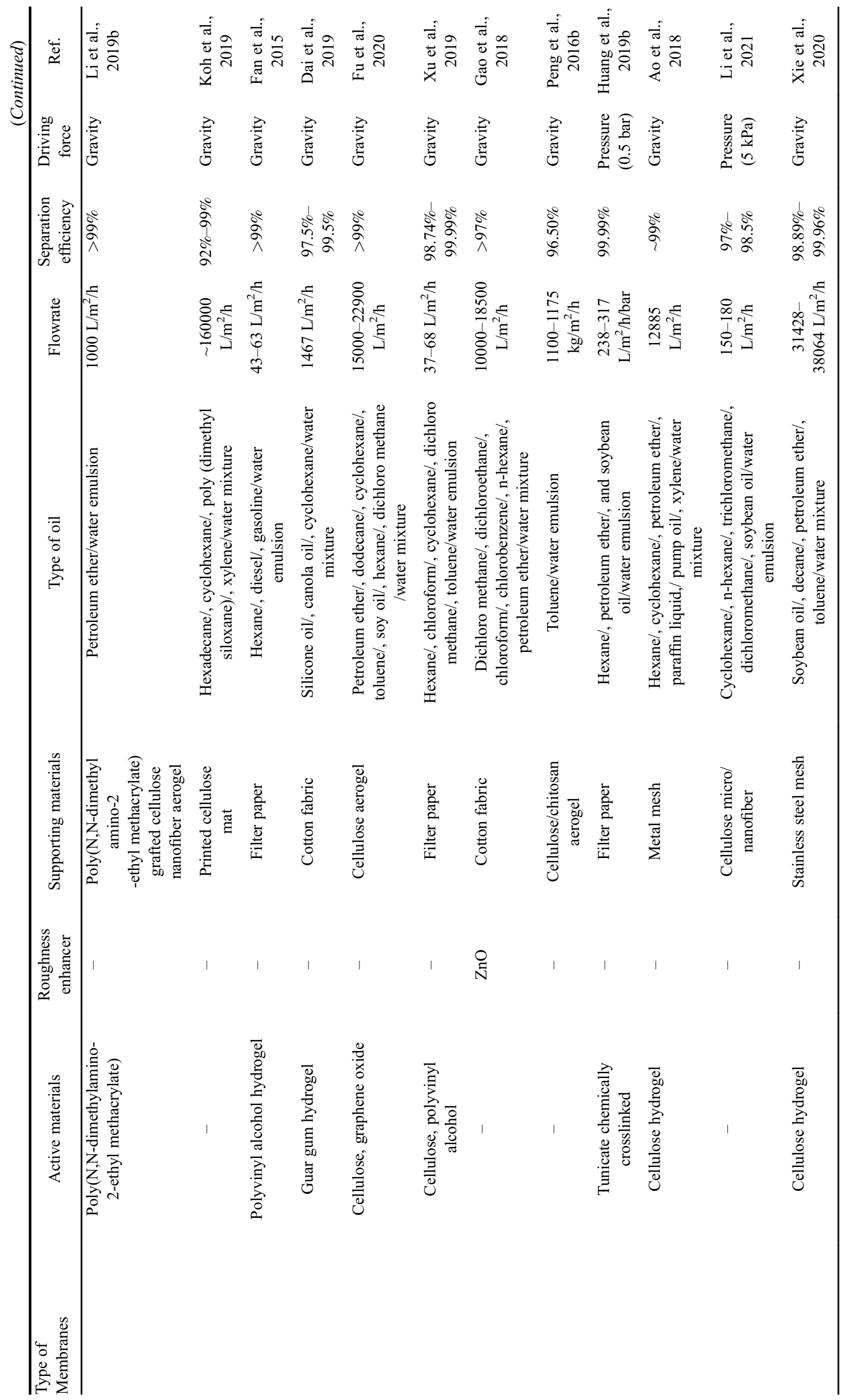




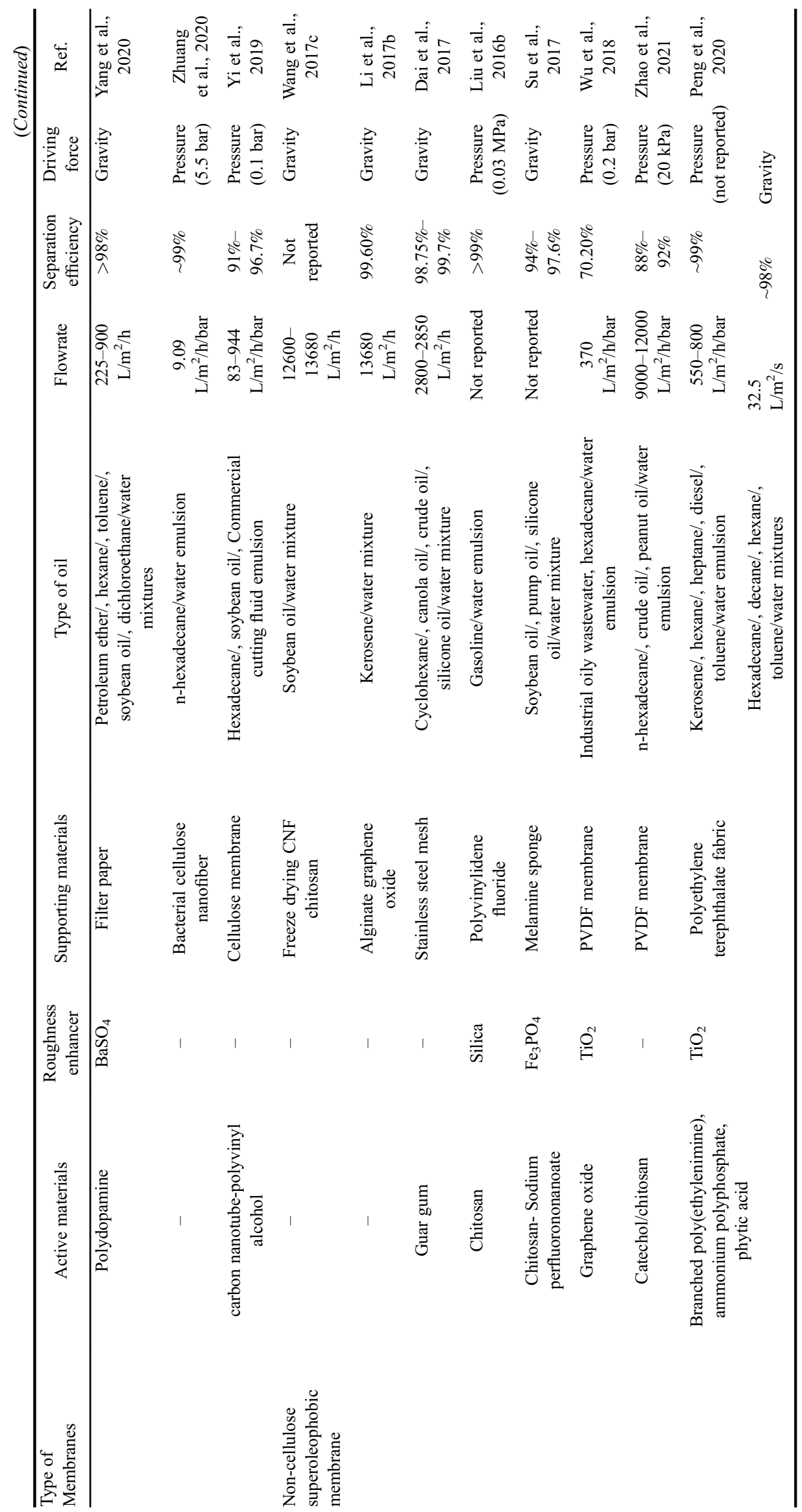





Fig. 10 (a) Photo image of water on the surface of a Salvinia leaf. (b) SEM image of Salvinia fur shows its superhydrophobic properties. However, a close look reveals its hydrophilic feature in that the drop's surface attracts to the top of the fur (c). (d) SEM image of Salvania fur with its hydrophilic function on the top and hydrophobic function on the bottom. (e) Photo image of Namib beetle. (f) Namib beetle's skin shows hydrophilic and hydrophobic feature. A Janus surface shows superhydrophilic on one side $(\mathrm{g})$ and superhydrophobic on another side (h). (a-d) Reproduced with permission. (Barthlott et al., 2010) Copyright 2010, Wiley-VCH. (e and f) Reproduced with permission. (Parker and Lawrence, 2001) Copyright 2001, Nature Publishing Group. (g and h) Reproduced with permission. (Wang et al., 2016e) Copyright 2016, Wiley-VCH.

and a hydrophobic surface on the other side. Janus membranes are categorized into three types, as depicted in Fig. 11(a) (Yang et al., 2016). Therefore, the separation mechanism of a Janus membrane is influenced by its type, functioning through demulsification and rejection employed during oil-water separation.

If we define $\mathrm{A}$ as the hydrophobic layer and $\mathrm{B}$ as the hydrophilic layer, for the "A and B" types, the A and B layers have a similar thickness. A third layer may exist between the A and B layers. Membranes of this type can separate either oil-in-water or water-in-oil emulsions, depending on which surface is in contact with the emulsion, as shown in Fig. 11(b). The hydrophilic face is suited to separating oil-in-water emulsions, and vise-versa; the hydrophobic face is suited to separating water-in-oil (Yue et al., 2018c; Lv et al., 2019). If the hydrophobic layer faces the feed, the membrane is able to separate water in oil. When the hydrophilic layer faces the feed, the membrane is able to separate oil in water emulsions. Therefore, Janus membranes are switchable depending on the type of wastewater. This principle of the "A and B" type is similar to superhydrophobic membranes or superoleophobic membranes, as previously discussed in parts 3 and 4, respectively. The "A and B" type has been reported by some researchers (Gore et al., 2016; Gupta and Kandasubramanian, 2017; Gore and Kandasubramanian, 2018; Yue et al., 2018c; Lv et al., 2019; Hu et al., 2020).

"A on B" and "B on A" mean the A layer is thinner than the $B$ layer, and the $B$ layer is thinner than the A layer, respectively. For A on B (Fig. 12(a)), the superhydrophobic surface retained oil (Tian et al., 2014). If moving in a positive direction, when water droplets contact the hydrophobic side, they spontaneously penetrate the surface due to its low breakthrough pressure. However, if the direction is reversed (Fig. 12(b)), when water droplets contact the hydrophilic side, they tend to spread and are blocked by the hydrophobic surface. This phenomenon shows that breakthrough pressure is affected by which side faces the wastewater. Furthermore, breakthrough pressure is also affected by the fluorine content as a hydrophobic polymer attached. Tian et al. (2014) have reported on the A on B type.

For B on A (Fig. 12(c)), water and oil droplets pass through the hydrophilic side. Yet, the water is retained in the superhydrophobic side, meaning only oil passes through. Wang et al. (Wang et al., 2016d, 2016e) have reported on the B on A type. The hydrophilic side of the Janus membrane disrupts the emulsion's stability by ionizing water, initiating coalescence of the oil droplets, and transporting them to the hydrophobic side (Wang et al., 2016d; 2016e). The hydrophobic side selectively permeates the oil. This mechanism allows the membrane to separate oil in water emulsions, although the membrane's pore size is larger than the oil droplets (Wang et al., 2016d). In terms of oil-water mixtures, the membrane could separate the mixture regardless of which side faces the feed (Wang et al., 2016e). If the hydrophilic side faces the feed, the water and oil pass through the hydrophilic side, but the water is retained on the hydrophobic side. If the hydrophobic side faces the feed, water is retained, and only oil passes through the membrane. However, the membrane could separate oil-in-water emulsions if only the hydrophilic side faces the feed. When the hydrophobic surface faces the feed, no liquid is allowed to permeate the membrane, as shown in Fig. 12(d).

\subsection{Preparation of Janus membranes}

There are not many publications on using Janus membranes from cellulose for oil-water applications. Figure 13 




Fig. 11 (a) Proposed type of Janus membrane. (b) Separation mechanism of A and B types. (b) Reproduced with permission. (Yue et al., 2018c) Copyright 2018, Springer Nature and Reproduced with permission. (Lv et al., 2019) Copyright 2019, American Chemical Society.

summarizes the general fabrication method of Janus membranes. Fabrication of Janus membranes is tedious, involving several steps, including coating, dissolution, and polymerization. Therefore, in situ fabrication reduces time and cost.

The A and B type was the most common type of Janus membrane reported. Membranes were fabricated by electrospinning on one side of cotton (Gore et al., 2016; Gore and Kandasubramanian, 2018), single-faced coating using a Meyer rod (Gupta and Kandasubramanian, 2017), floated deposition ( $\mathrm{Hu}$ et al., 2020), sequential surface modification (Lv et al., 2019), and vacuum filtration (Yue et al., 2018c). Sodium laurate (Yue et al., 2018c) or stearic acid (Lv et al., 2019) were used for the hydrophobic side, and $\mathrm{MnO}_{2}$ (Yue et al., 2018c) or immobilized Ag (Lv et al., 2019) were used for the hydrophilic surface. $\mathrm{ZnO}$ (Yue et al., 2018c), Ag (Lv et al., 2019), nanoclay (Gore and Kandasubramanian, 2018) particles were used as roughness enhancers. Subsequently, the cellulose fabric was immersed in the Ag solution and stearic acid while one side was protected by attaching tape. The hydroxyl group on the surface of the $\mathrm{ZnO}$ underwent a crosslinking reaction with sodium laurate. The $\mathrm{ZnO}$ was coated by in situ hydrothermal precipitation while an $\mathrm{MnO}_{2}$ nanowire was fabricated hydrothermally, followed by deposition on one side using a vacuum.

The A on B type was fabricated using vapor treatment (Tian et al., 2014). In this system, the membrane is made of woven cotton vaporized with $1 \mathrm{H}, 1 \mathrm{H}, 2 \mathrm{H}, 2 \mathrm{H}$-perfluoro octyl trichlorosilane (POTS) (Tian et al., 2014). A POTS was placed inside of a crystallizing dish then covered with cotton fabric with a distance of $\sim 6 \mathrm{~cm}$ between the POTS and cotton fabric. A glass plate was used to press the cotton fabric. The POTS vapor then diffused and reacted with the hydroxyl group of cotton by a salinization reaction.

The B on A type was fabricated using single-faced photo crosslinking (Wang et al., 2016e) and segment immigration (Wang et al., 2016d). The cotton fabric was coated with PDMAEMA (Poly(N,N dimethyl aminoethyl methacrylate)) and PDMS (poly(dimethylsiloxane)) to create a 


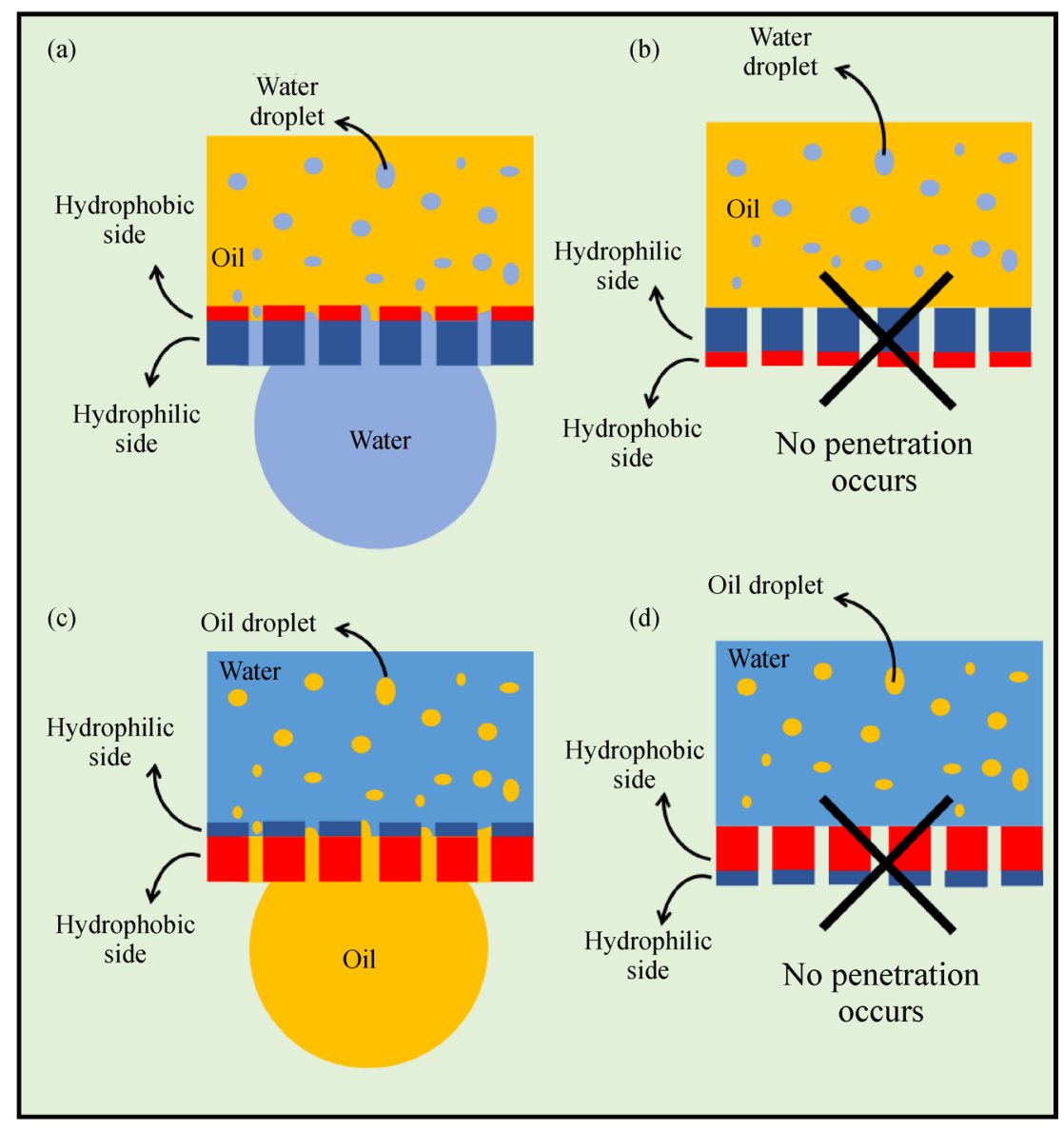

Fig. 12 Separation mechanism of A on B and B on A with A as hydrophobic and B as hydrophilic. A on B is suited to separating waterin-oil emulsions when the A layer faces the feed (a) and no penetration occurs when the B layer faces the feed (b). B on A type is suited to separating oil-in-water emulsions when the B layer faces the feed (c) but no penetration occurs when the A layer faces the feed (d).

hydrophilic and hydrophobic side (Wang et al., 2016e). First, the cotton was coated with diblock copolymer PDMS- $b$-PCEA, with PCEA referring to poly(2-cinnamoyloxyethyl acrylate). The polymer was then crosslinked using irradiation, followed by uncross-linked polymer extraction with hot tetrahydrofuran (THF). The fabric was then coated with trimethoxysilyl propyl methacrylate (TMSPMA) and PDMAEMA (Wang et al., 2016e). During segment immigration, the cotton was coated with a diblock copolymer of P1- $b$-Am. P1 refers to P(MMA-sHEMA)-g-PDMS, and Am refers to PDMAEMA. MMA and HEMA refer to methyl methacrylate and 2-hydroxyethyl methacrylate, respectively. The hydrophilic hairy brush PDMAEMA would rise to the top of the PDMS when in contact with water, creating a Janus structure (Wang et al., 2016d).

\subsection{Performance of Janus membranes}

Similar to the two previous membranes, the performance of Janus membranes is evaluated based on several criteria, including wettability, separation efficiency, flow rate, and how they maintain their wettability, separation efficiency, and flow rate when exposed to various different conditions. The previous methods used for superhydrophobic and superoleophobic membranes are also applicable for the Janus membrane. For instance, to evaluate the membrane's performance under harsh conditions, a saline solution with a $\mathrm{NaCl}$ concentration of $10 \%-40 \%$ (Gore and Kandasubramanian, 2018), at a low temperature $\left(-20^{\circ} \mathrm{C}\right.$ to $\left.0^{\circ} \mathrm{C}\right)$ (Gupta and Kandasubramanian, 2017; Gore and Kandasubramanian, 2018) was used. A and B types are capable of separating oil-water mixtures (Gore et al., 2016; Gupta and Kandasubramanian, 2017; Gore and Kandasubramanian, 2018; Hu et al., 2020), oil-in-water (Yue et al., 2018c; Lv et al., 2019), or water-in-oil (Yue et al., 2018c; Lv et al., 2019), depending on the materials and fabrication methods used. The A on B type, and B on A type are more common than the A and $B$ type, especially to separate oil-in-water or a water-in-oil emulsions. B on A has a high water flux of $1.5 \times 10^{3} \mathrm{~L} / \mathrm{m}^{2} / \mathrm{h}$ and a separation efficiency of almost $100 \%$. Hexadecane, toluene, and chlorobenzene were used as oil models at concentrations ranging from $1.0 \%$ to $30 \%$ (Wang et al., 2016e). This high flux may be due to the pore 


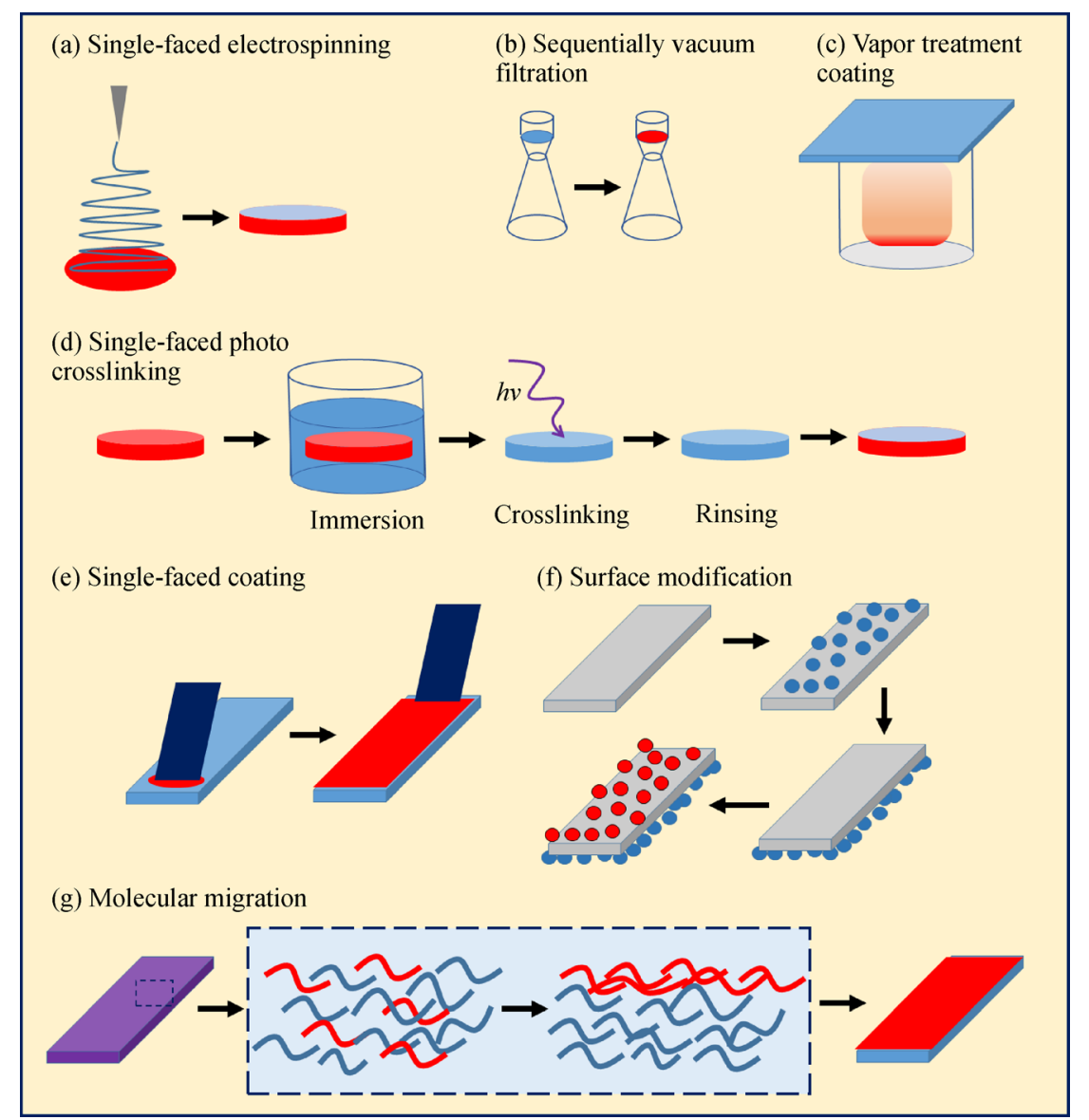

Fig. 13 Schematic diagram of Janus fabrication method for single-face electrospinning (a), sequentially vacuum filtration (b), vapor treatment coating (c), single-faced photo crosslinking (d), single-faced coating (e), surface modification (f) and molecular migration (g).

size of the filter being higher than that of the oil droplets (Wang et al., 2016d). Table 4 summaries the several Janus membranes.

\section{Summary and outlook}

Three kinds of membranes were summarized based on their surface wettability. Superhydrophobic membranes penetrate oil and reject water. Therefore, superhydrophobic membranes are suited to water-in-oil systems. Superhydrophobic membrane suits when oil collecting is preferred, for instance, oil collecting of oil spill accident or high oil content wastewater. Oil contaminants will be adsorbed leaving cleaner water. The superhydrophobic membrane provides an efficient and continuous process compares to the aerogel adsorbent. However, most industrial oily wastewater is an oil-in-water emulsion or light oil-water mixture so that oil collecting is insufficient and water collecting is preferred.

Superoleophobic membranes reject oil and penetrate water. Therefore, superoleophobic membranes are suited to oil-in-water systems such as household wastewater, refinery process, food processing industries, petrochemical industries, tannery industries, or steel processing industries. The organic oil contaminant could be fats, kerosene, diesel, gasoline, or other types of hydrocarbons. In terms of high viscous oil contaminants, the superoleophobic membrane will decrease the pressure drop because low viscous water will pass through the membrane. Furthermore, due to the water mostly has a higher density than oil, the separation system can be arranged to utilize gravitational force alone. The oleophobic characteristic also repels the non-polar substance minimizing fouling tendency.

However, both superhydrophobic and superoleophobic membranes require smaller or comparable pore size to droplet diameter. Therefore, the high flow rate is a trade-off for low separation efficiency. Janus membranes can separate oil droplets even when the pore size is larger than the oil droplets. Janus membranes tend to be more effective at separation, and the flowrate is comparable to superhydrophobic and superoleophobic cellulose-based membranes. However, further experimentation is necessary due to the lack of literature and theoretical knowledge on cellulose-based Janus membranes. Comparison to the 
Table 4 Summary of Janus membranes

\begin{tabular}{|c|c|c|c|c|c|c|c|c|}
\hline \multicolumn{2}{|c|}{ Active materials } & \multirow{2}{*}{$\begin{array}{l}\text { Roughness } \\
\text { enhancer }\end{array}$} & \multirow{2}{*}{$\begin{array}{c}\text { Supporting } \\
\text { materials }\end{array}$} & \multirow[b]{2}{*}{ Type of oil } & \multirow[b]{2}{*}{ Flowrate } & \multirow{2}{*}{$\begin{array}{l}\text { Separation } \\
\text { efficiency }\end{array}$} & \multirow{2}{*}{$\begin{array}{l}\text { Driving } \\
\text { force }\end{array}$} & \multirow[b]{2}{*}{ Ref. } \\
\hline $\begin{array}{c}\text { Hydrophobic } \\
\text { part }\end{array}$ & Hydrophilic part & & & & & & & \\
\hline $\begin{array}{l}\text { Poly(dimethyl } \\
\text { siloxane) }\end{array}$ & $\begin{array}{l}\text { Poly (N,Ndimethyl } \\
\text { amino } \\
\text { ethylmethacrylate) }\end{array}$ & None & $\begin{array}{l}\text { Cotton } \\
\text { fabric }\end{array}$ & $\begin{array}{c}\text { Toluene/, hexadecane/, } \\
\text { chlorobenzene/water } \\
\text { emulsion }\end{array}$ & $\begin{array}{c}490-6700 \\
\mathrm{~L} / \mathrm{m}^{2} / \mathrm{h}\end{array}$ & $\begin{array}{c}\text { Not } \\
\text { reported }\end{array}$ & Gravity & $\begin{array}{l}\text { Wang } \\
\text { et al., } \\
2016 \mathrm{~d}\end{array}$ \\
\hline $\begin{array}{l}\text { Poly(dimethyl } \\
\text { siloxane) }\end{array}$ & $\begin{array}{l}\text { Poly (N,Ndimethyl } \\
\text { amino } \\
\text { ethylmethacrylate) }\end{array}$ & None & $\begin{array}{l}\text { Cotton } \\
\text { fabric }\end{array}$ & $\begin{array}{l}\text { Toluene/, hexane/, } \\
\text { hexadecane/, } \\
\text { chlorobenzene/water } \\
\text { emulsion }\end{array}$ & $\begin{array}{c}1500-10500 \\
\mathrm{~L} / \mathrm{m}^{2} / \mathrm{h}\end{array}$ & $\begin{array}{l}\text { Not } \\
\text { reported }\end{array}$ & Gravity & $\begin{array}{l}\text { Wang } \\
\text { et al., } \\
2016 \mathrm{e}\end{array}$ \\
\hline \multirow[t]{2}{*}{ Sodium laurate } & $\mathrm{MnO}_{2}$ nanowire & $\begin{array}{l}\mathrm{ZnO} \text { nanorod } \\
\text { and } \mathrm{MnO}_{2} \\
\text { nanowire }\end{array}$ & $\begin{array}{l}\text { Filter } \\
\text { paper }\end{array}$ & $\begin{array}{c}\text { Emulsion of water/ } \\
\text { hexadecane, water/toluene, } \\
\text { water/chloroform, /diesel }\end{array}$ & $\begin{array}{l}1590-8840 \\
\mathrm{~L} / \mathrm{m}^{2} / \mathrm{h} / \mathrm{bar}\end{array}$ & $99.40 \%$ & $\begin{array}{l}\text { Pressure } \\
(0.03 \mathrm{MPa})\end{array}$ & $\begin{array}{l}\text { Yue } \\
\text { et al., } \\
2018 \mathrm{c}\end{array}$ \\
\hline & & & & $\begin{array}{l}\text { Hexadecane/water, } \\
\text { toluene/, chloroform/, } \\
\text { diesel/water emulsions }\end{array}$ & $\begin{array}{c}8380-13740 \\
\mathrm{~L} / \mathrm{m}^{2} / \mathrm{h} / \mathrm{bar}\end{array}$ & $99.80 \%$ & $\begin{array}{l}\text { Pressure } \\
(0.03 \mathrm{MPa})\end{array}$ & \\
\hline \multirow{2}{*}{$\begin{array}{l}\text { Methyl } \\
\text { trimethoxy } \\
\text { silane } \\
\text { crosslinked } \\
\text { cellulose } \\
\text { nanofiber }\end{array}$} & $\begin{array}{l}\text { 3-glycidoxy } \\
\text { propyl trimethoxy } \\
\text { silane crosslinked } \\
\text { cellulose nanofiber }\end{array}$ & None & $\begin{array}{c}\mathrm{CNF} \\
\text { aerogel }\end{array}$ & $\begin{array}{l}\text { Mixture of water/toluene, } \\
\text { /dichloromethane, } \\
\text { /tetrahydrofuran, } \\
\text { /n-hexane }\end{array}$ & $\begin{array}{c}1200-3200 \\
\mathrm{~L} / \mathrm{m}^{2} / \mathrm{h}\end{array}$ & $40 \%-99 \%$ & Gravity & $\begin{array}{l}\text { Agaba } \\
\text { et al., } \\
2021\end{array}$ \\
\hline & & None & & $\begin{array}{c}\text { Toluene/, } \\
\text { dichloromethane/, } \\
\text { tetrahydrofuran/, } \\
\text { n-hexane/ water mixture }\end{array}$ & $\begin{array}{c}1400-2600 \\
\mathrm{~L} / \mathrm{m}^{2} / \mathrm{h}\end{array}$ & $50 \%-90 \%$ & Gravity & \\
\hline $\begin{array}{l}\text { Poly lactic acid, } \\
\text { nano clay }\end{array}$ & Cellulose & Nano clay & $\begin{array}{l}\text { Cotton } \\
\text { fabric }\end{array}$ & $\begin{array}{c}\text { Diesel/, petrol/, n-hexane/, } \\
\text { toluene/, xylene/water } \\
\text { mixture }\end{array}$ & $\begin{array}{c}11000-32000 \\
\mathrm{~L} / \mathrm{m}^{2} / \mathrm{h}\end{array}$ & $95 \%-99 \%$ & Gravity & $\begin{array}{l}\text { Gore } \\
\text { et al., } \\
2018\end{array}$ \\
\hline \multirow[t]{2}{*}{$\begin{array}{l}\text { Octadecyl } \\
\text { triethoxysilane }\end{array}$} & $\mathrm{MnO}_{2}$ & $\begin{array}{c}\mathrm{Co}\left(\mathrm{CO}_{3}\right) \cdot 0.5 \mathrm{OH} \\
\cdot 0.11 \mathrm{H}_{2} \mathrm{O} \\
\text { nanoneedle }\end{array}$ & $\begin{array}{l}\text { Cotton } \\
\text { fabric }\end{array}$ & $\begin{array}{c}\text { Hexane/, toluene/, } \\
\text { dodecane/, diesel/water } \\
\text { mixture }\end{array}$ & $7187 \mathrm{~L} / \mathrm{m}^{2} / \mathrm{h}$ & $\sim 98 \%$ & Gravity & $\begin{array}{l}\mathrm{Hu} \\
\text { et al., } \\
2020\end{array}$ \\
\hline & & & & $\begin{array}{l}\text { Mixture of water/ } \\
\text { dichloromethane, } \\
\text { /carbon tetrachloride }\end{array}$ & $\begin{array}{c}70200-77760 \\
\mathrm{~L} / \mathrm{m}^{2} / \mathrm{h}\end{array}$ & $\sim 98 \%$ & Gravity & \\
\hline \multirow[t]{2}{*}{ Stearic acid } & Cellulose & Ag nanoparticle & $\begin{array}{l}\text { Cellulose } \\
\text { membrane }\end{array}$ & $\begin{array}{c}\text { Toluene/, carbon } \\
\text { tetrachloride/, hexane/, } \\
\text { chloroform/, } \\
\text { dichloromethane/ } \\
\text { water emulsion }\end{array}$ & $\begin{array}{c}623.5-685.2 \\
\mathrm{~L} / \mathrm{m}^{2} / \mathrm{h}\end{array}$ & $\begin{array}{c}95.62 \%- \\
97.25 \%\end{array}$ & Gravity & $\begin{array}{l}\text { Lv } \\
\text { et al., } \\
2019\end{array}$ \\
\hline & & & & $\begin{array}{l}\text { Water/toluene, /carbon } \\
\text { tetrachloride, /hexane, } \\
\text { /chloroform, } \\
\text { /dichloromethane } \\
\text { emulsion }\end{array}$ & $\begin{array}{c}296.6-345.2 \\
\mathrm{~L} / \mathrm{m}^{2} / \mathrm{h}\end{array}$ & $\begin{array}{l}95.25 \%- \\
98.32 \%\end{array}$ & Gravity & \\
\hline
\end{tabular}

commercial and actual oily wastewater are summarized in Table 5. In general, superhydrophobic, superoleophobic and Janus membranes show relatively higher flux and separation efficiency.

The laboratory-scale and homemade oily wastewater model show successful results, but the membranes have not been fully implemented in actual oily wastewater treatment. Many challenges must be overcome to fill the gap between theory and experimentation at the laboratory scale and industrial application, such as the physical strength of materials, the biodegradability of materials, leaching from used nanoparticles, reusability, modules fabrication, and actual oily wastewater treatment. Even though cellulose is biodegradable, additive materials used to advance its functionality are still non-biodegradable. The life cycle assessment has to be conducted especially for composite membrane. Nanoparticle leaching must be considered, especially when using metal or potentially toxic chemicals. Reusability and membrane fouling are related to the wettability of the membrane. Current research conduct testing for approximately hundreds of filtration times. Batch and non-module separation system are used for evaluation on a laboratory scale. However, on an industrial scale, module and continuous systems are 
Table 5 Commercial and non-superoleophobic, non-superhydrophobic, and non-Janus membrane performance

\begin{tabular}{|c|c|c|c|c|c|c|c|}
\hline Manufacturer & Material & Type of oil & $\begin{array}{l}\text { Membrane } \\
\text { specification }\end{array}$ & Flux & $\begin{array}{l}\text { Rejection/ } \\
\text { Separation } \\
\text { efficiency }\end{array}$ & $\begin{array}{l}\text { Driving } \\
\text { force }\end{array}$ & Ref. \\
\hline $\begin{array}{l}\text { EMD Millipore } \\
\text { Corporation, USA }\end{array}$ & Not reported & $\begin{array}{l}\text { Industrial oily } \\
\text { wastewater }\end{array}$ & $\begin{array}{l}\text { MWCO } \\
30 \mathrm{kDa}\end{array}$ & $46 \mathrm{~L} / \mathrm{m}^{2} / \mathrm{h} / \mathrm{bar}$ & $65.30 \%$ & $\begin{array}{l}\text { Pressure } \\
(0.2 \text { bar })\end{array}$ & $\begin{array}{l}\text { Wu et al., } \\
2018\end{array}$ \\
\hline $\begin{array}{l}\text { Merck Millipore CO., } \\
\text { LTD, Germany }\end{array}$ & PVDF membrane & $\begin{array}{l}\text { Commercial cutting } \\
\text { fluid emulsion }\end{array}$ & $0.1 \mu \mathrm{m}$ & $36-163 \mathrm{~L} / \mathrm{m}^{2} / \mathrm{h} / \mathrm{bar}$ & $91.30 \%$ & $\begin{array}{l}\text { Pressure } \\
(0.1 \text { bar })\end{array}$ & $\begin{array}{l}\text { Yi et al., } \\
2019\end{array}$ \\
\hline Pall Corporation, USA & PES membrane & $\begin{array}{l}\text { Commercial cutting } \\
\text { fluid emulsion }\end{array}$ & $0.2 \mu \mathrm{m}$ & $39-216 \mathrm{~L} / \mathrm{m}^{2} / \mathrm{h} / \mathrm{bar}$ & $85.30 \%$ & & \\
\hline PCI-Memtech, UK & $\begin{array}{l}\text { PVDF Ultrafiltration } \\
\text { membrane }\end{array}$ & POME & $\begin{array}{l}\text { MWCO } \\
200 \mathrm{kDa}\end{array}$ & $20-70 \mathrm{~L} / \mathrm{m}^{2} / \mathrm{h}$ & $17 \%$ & $\begin{array}{l}\text { Pressure } \\
\text { ( } 2 \text { bar })\end{array}$ & $\begin{array}{c}\text { Ahmad } \\
\text { et al., } 2006\end{array}$ \\
\hline PCI-Memtech, UK & TFC Reverse Osmosis & POME & $\begin{array}{l}99 \% \mathrm{NaCl} \\
\text { retension }\end{array}$ & $40-80 \mathrm{~L} / \mathrm{m}^{2} / \mathrm{h}$ & $99.30 \%$ & $\begin{array}{l}\text { Pressure } \\
(45 \text { bar) }\end{array}$ & \\
\hline $\begin{array}{l}\text { Laboratory fabrication, } \\
\text { China }\end{array}$ & $\begin{array}{l}\text { PVDF ultrafiltration } \\
\text { membranes } \\
\text { hydrophilized by } \\
\mathrm{Al}_{2} \mathrm{O}_{3} \text { nanoparticles }\end{array}$ & $\begin{array}{l}\text { Wastewater from } \\
\text { polymer flooding }\end{array}$ & $\begin{array}{c}\text { Not } \\
\text { reported }\end{array}$ & $45-150 \mathrm{~L} / \mathrm{m}^{2} / \mathrm{h}$ & $\begin{array}{c}89.5 \%- \\
94 \%\end{array}$ & $\begin{array}{l}\text { Pressure } \\
(0.2 \mathrm{MPa})\end{array}$ & $\begin{array}{l}\text { Xu et al., } \\
2016\end{array}$ \\
\hline $\begin{array}{l}\text { Laboratory fabrication, } \\
\text { China }\end{array}$ & $\begin{array}{l}\text { PVDF ultrafiltration } \\
\text { membranes } \\
\text { hydrophilized by } \\
\mathrm{Al}_{2} \mathrm{O}_{3} \text { nanoparticles }\end{array}$ & $\begin{array}{l}\text { the Daqing oil } \\
\text { field wastewater }\end{array}$ & $\begin{array}{l}\text { MWCO } \\
35 \mathrm{kDa}\end{array}$ & $150-170 \mathrm{~L} / \mathrm{m}^{2} / \mathrm{h}$ & $\sim 98 \%$ & $\begin{array}{c}\text { Pressure } \\
(0.1 \mathrm{MPa})\end{array}$ & $\begin{array}{l}\text { Li et al., } \\
2006\end{array}$ \\
\hline DOW CO., Denmark & Polysulfone & $\begin{array}{l}\text { Industrial oily } \\
\text { wastewaters }\end{array}$ & $\begin{array}{l}\text { MWCO } \\
30 \mathrm{kDa}\end{array}$ & $32.1 \mathrm{~L} / \mathrm{m}^{2} / \mathrm{h}$ & $97 \%$ & $\begin{array}{l}\text { Pressure } \\
(3 \text { bar })\end{array}$ & $\begin{array}{c}\text { Salahi et al., } \\
2010\end{array}$ \\
\hline Sepromembranes, USA & Polyacrilonitrile & & $\begin{array}{l}\text { MWCO } \\
20 \mathrm{kDa}\end{array}$ & $53.7 \mathrm{~L} / \mathrm{m}^{2} / \mathrm{h}$ & $99.70 \%$ & & \\
\hline Osmonics, USA & Polyacrilonitrile & & $\begin{array}{l}\text { MWCO } \\
100 \mathrm{kDa}\end{array}$ & $96.2 \mathrm{~L} / \mathrm{m}^{2} / \mathrm{h}$ & $97.20 \%$ & & \\
\hline Alfa Laval, Denmark & Polysulfone & & $0.1 \mu \mathrm{m}$ & $76 \mathrm{~L} / \mathrm{m}^{2} / \mathrm{h}$ & $95 \%$ & & \\
\hline DOW CO., Denmark & Polysulfone & & $0.2 \mu \mathrm{m}$ & $73.1 \mathrm{~L} / \mathrm{m}^{2} / \mathrm{h}$ & $66.30 \%$ & & \\
\hline
\end{tabular}

mainly used. Finally, membrane reusability has to be accounted for both economic and technical assessment.

Acknowledgements This research was supported in part by a Kurita Asia Research Grant (20Pid001) provided by Kurita Water and Environment Foundation (Japan) and was supported by JSPS KAKENHI Grant Number 17KT0069 (Japan).

Open Access This article is licensed under a Creative Commons Attribution 4.0 International License, which permits use, sharing, adaptation, distribution and reproduction in any medium or format, as long as you give appropriate credit to the original author(s) and the source, provide a link to the Creative Commons licence, and indicate if changes were made. The images or other third party material in this article are included in the article's Creative Commons licence, unless indicated otherwise in a credit line to the material. If material is not included in the article's Creative Commons licence and your intended use is not permitted by statutory regulation or exceeds the permitted use, you will need to obtain permission directly from the copyright holder. To view a copy of this licence, visit http://creativecommons.org/licenses/by/4.0/.

\section{Appendix}

$\begin{array}{ll}\mathrm{AlOOH} & \begin{array}{l}\text { Aluminum hydroxide oxide } \\ \mathrm{BaSO}_{4}\end{array} \\ \mathrm{BOD} & \begin{array}{l}\text { Barium sulfate } \\ \text { Biological oxygen demand }\end{array}\end{array}$

$\mathrm{CNC}$

$\mathrm{CNF}$

PEI

CNT

$\mathrm{CO}_{2}$

COD

CTAB

$\mathrm{Cu}$

ESO

FAS

$\mathrm{Fe}_{3} \mathrm{O}_{4}$

FTIR

GG

GO

$\mathrm{HCl}$

HEMA

MBA

MMA

MWCO

$\mathrm{Na}_{2} \mathrm{SO}_{4} \cdot 10 \mathrm{H}_{2} \mathrm{O}$
We included the cellulose nanocrystal

Cellulose nanofiber

poly(ethyleneimine)

Carbon nanotube

Carbon dioxide

Chemical oxygen demand

Hexadecyltrimethylammonium bromide

Copper

Epoxidized soybean oil

(pentaflurophenyl)triethoxy silane

Iron oxide

Fourier transfer infrared

Guar Gum

Graphene oxide

Hydrogen chloride

2-hydroxyethyl methacrylate

$\mathrm{N}$-methylenebisacrylamide

Methyl methacrylate

Molecular weight cut off

Sodium sulfate decahydrate 


\begin{tabular}{|c|c|}
\hline $\mathrm{Na}_{3} \mathrm{PO}_{4}$ & Trisodium phosphate \\
\hline $\mathrm{NaCl}$ & Sodium chloride \\
\hline $\mathrm{NaClO}_{2}$ & Sodium chlorite \\
\hline $\mathrm{NaIO}_{4}$ & Sodium periodate \\
\hline $\mathrm{NaOH}$ & Sodium hidroxyde \\
\hline OCA & Oil contact angle \\
\hline OTS & Octadecyl silane \\
\hline PANI & polyaniline \\
\hline PCEA & poly(2-cinnamoyloxyethyl acrylate) \\
\hline PDMAEMA & poly(N,N dimethyl aminoethyl methacrylate) \\
\hline PDMS & poly(dimethylsiloxane) \\
\hline PDMS- $b$-PEO & poly(dimethylsiloxane)-b-poly(ethylene oxide) \\
\hline PEI & poly(ethyleneimine) \\
\hline $\mathrm{pH}$ & Potential of hydrogen or power of hydrogen \\
\hline POME & Palm oil mill effluent \\
\hline POTS & $1 \mathrm{H}, 1 \mathrm{H}, 2 \mathrm{H}, 2 \mathrm{H}$-perfluoro octyl trichlorosilane \\
\hline PS & Polystyrene \\
\hline PTES & $\begin{array}{l}1 \mathrm{H}, 1 \mathrm{H}, 2 \mathrm{H}, 2 \mathrm{H}-\text { perfluorooctyltriethoxysilane } \\
\left(\mathrm{C}_{14} \mathrm{H}_{19} \mathrm{~F}_{13} \mathrm{O}_{3} \mathrm{Si}\right)\end{array}$ \\
\hline PVDF & poly(vinylidene fluoride) \\
\hline PVDF-HFP & polyvinylidene fluoride-co-hexafluoropropylene \\
\hline RH & Relative humidity \\
\hline SDS & Sodium dodecyl sulfate \\
\hline SEM & Scanning electron microscopy \\
\hline $\mathrm{SiO}_{2}$ & silicon oxide \\
\hline TEMPO & 2,2,6,6-tetramethylpiperidine-1-oxylradical \\
\hline TG-TGA & $\begin{array}{l}\text { Thermogravimetric analysis or thermal gravimetric } \\
\text { analysis }\end{array}$ \\
\hline THF & tetrahydrofuran \\
\hline $\mathrm{TiO}_{2}$ & Titanium dioxide \\
\hline TMSPMA & trimethoxysilyl propyl methacrylate \\
\hline TOCNF & TEMPO-oxidized cellulose nanofibril \\
\hline Tween 80 & polysorbate 80 (Tween 80 ) \\
\hline UV & Ultra-Violet \\
\hline WCO & Water contact angle \\
\hline XPS & Photoelectron spectroscopy \\
\hline $\mathrm{XRD}$ & X-Ray Diffraction \\
\hline $\mathrm{ZnO}$ & Zinc Oxide \\
\hline
\end{tabular}

\section{References}

Agaba A, Marriam I, Tebyetekerwa M, Yuanhao W (2021). Janus hybrid sustainable all-cellulose nanofiber sponge for oil-water separation. International Journal of Biological Macromolecules, 185: 997-1004

Ahmad A L, Chong M F, Bhatia S, Ismail S (2006). Drinking water reclamation from palm oil mill effluent (POME) using membrane technology. Desalination, 191(1-3): 35-44
Ahmed F E, Lalia B S, Hilal N, Hashaikeh R (2014). Underwater superoleophobic cellulose/electrospun PVDF-HFP membranes for efficient oil/water separation. Desalination, 344: 48-54

Almeida A P, Oliveira J, Fernandes S N, Godinho M H, Canejo J P (2020). All-cellulose composite membranes for oil microdroplet collection. Cellulose, 27(8): 4665-4677

Ao C, Hu R, Zhao J, Zhang X, Li Q, Xia T, Zhang W, Lu C (2018). Reusable, salt-tolerant and superhydrophilic cellulose hydrogelcoated mesh for efficient gravity-driven oil/water separation. Chemical Engineering Journal, 338: 271-277

Ao C, Yuan W, Zhao J, He X, Zhang X, Li Q, Xia T, Zhang W, Lu C (2017). Superhydrophilic graphene oxide@electrospun cellulose nanofiber hybrid membrane for high-efficiency oil/water separation. Carbohydrate Polymers, 175: 216-222

Arslan O, Aytac Z, Uyar T (2016). Superhydrophobic, hybrid, electrospun cellulose acetate nanofibrous mats for oil/water separation by tailored surface modification. ACS Applied Materials \& Interfaces, 8(30): 19747-19754

Arumugam V, Kanthapazham R, Zherebtsov D A, Kalimuthu K, Pichaimani P, Muthukaruppan A (2021). Fluorine free $\mathrm{TiO}_{2}$ /cyanate ester coated cotton fabric with low surface free energy and rough surface for durable oil-water separation. Cellulose, 28(8): 48474863

Ashrafi Z, Hu Z, Lucia L, Krause W (2021). Bacterial superoleophobic fibrous matrices: A naturally occurring liquid-infused system for oilwater separation. Langmuir, 37(8): 2552-2562

Barthlott W, Schimmel T, Wiersch S, Koch K, Brede M, Barczewski M, Walheim S, Weis A, Kaltenmaier A, Leder A, Bohn H F (2010). The salvinia paradox: Superhydrophobic surfaces with hydrophilic pins for air retention under water. Advanced Materials, 22(21): 23252328

Bellanger H, Darmanin T, Taffin de Givenchy E, Guittard F (2014). Chemical and physical pathways for the preparation of superoleophobic surfaces and related wetting theories. Chemical Reviews, 114(5): 2694-2716

Bhushan B, Nosonovsky M (2010). The rose petal effect and the modes of superhydrophobicity. Philosophical Transactions of the Royal Society A: Mathematical, Physical and Engineering Sciences, 368(1929): 4713-4728

Brown P S, Bhushan B (2016). Bioinspired materials for water supply and management: water collection, water purification and separation of water from oil. Philosophical Transactions. Series A, Mathematical, Physical, and Engineering Sciences, 374(2073): 20160135

Cassie A B D, Baxter S (1944). Wettability of porous surfaces. Transactions of the Faraday Society, 40: 546-551

Cha T G, Yi J W, Moon M W, Lee K R, Kim H Y (2010). Nanoscale patterning of microtextured surfaces to control superhydrophobic robustness. Langmuir, 26(11): 8319-8326

Chen X, Weibel J A, Garimella S V (2015). Exploiting microscale roughness on hierarchical superhydrophobic copper surfaces for enhanced dropwise condensation. Advanced Materials Interfaces, 2(3): 1400480

Cheng G, Liao M, Zhao D, Zhou J (2017a). Molecular understanding on the underwater oleophobicity of self-assembled monolayers: zwitterionic versus nonionic. Langmuir, 33(7): 1732-1741 
Cheng Q, Ye D, Chang C, Zhang L (2017b). Facile fabrication of superhydrophilic membranes consisted of fibrous tunicate cellulose nanocrystals for highly efficient oil/water separation. Journal of Membrane Science, 525: 1-8

Cheng Q Y, An X P, Li Y D, Huang C L, Zeng J B (2017c). Sustainable and biodegradable superhydrophobic coating from epoxidized soybean oil and $\mathrm{ZnO}$ nanoparticles on cellulosic substrates for efficient oil/water separation. ACS Sustainable Chemistry \& Engineering, 5(12): 11440-11450

Cheng Q Y, Guan C S, Wang M, Li Y D, Zeng J B (2018a). Cellulose nanocrystal coated cotton fabric with superhydrophobicity for efficient oil/water separation. Carbohydrate Polymers, 199: 390-396

Cheng Q Y, Liu M C, Li Y D, Zhu J, Du A K, Zeng J B (2018b). Biobased super-hydrophobic coating on cotton fabric fabricated by spray-coating for efficient oil/water separation. Polymer Testing, 66: 41-47

Cho W K, Choi I S (2008). Fabrication of hairy polymeric films inspired by geckos: Wetting and high adhesion properties. Advanced Functional Materials, 18(7): 1089-1096

Chu Z, Feng Y, Seeger S (2015). Oil/water separation with selective superantiwetting/superwetting surface materials. Angewandte Chemie (International ed. in English), 54(8): 2328-2338

D’Odorico P, Davis K F, Rosa L, Carr J A, Chiarelli D, Dell'Angelo J, Gephart J, MacDonald G K, Seekell D A, Suweis S, Rulli M C (2018). The global food-energy-water nexus. Reviews of Geophysics, 56(3): 456-531

Dai L, Cheng T, Wang Y, Wang B, Duan C, Ke H, Ni Y (2019). A selfassembling guar gum hydrogel for efficient oil/water separation in harsh environments. Separation and Purification Technology, 225: 129-135

Dai L, Wang B, An X, Zhang L, Khan A, Ni Y (2017). Oil/water interfaces of guar gum-based biopolymer hydrogels and application to their separation. Carbohydrate Polymers, 169: 9-15

Ensikat H J, Ditsche-Kuru P, Neinhuis C, Barthlott W (2011). Superhydrophobicity in perfection: the outstanding properties of the lotus leaf. Beilstein Journal of Nanotechnology, 2(1): 152-161

Fan J B, Song Y, Wang S, Meng J, Yang G, Guo X, Feng L, Jiang L (2015). Directly coating hydrogel on filter paper for effective oilwater separation in highly acidic, alkaline, and salty environment. Advanced Functional Materials, 25(33): 5368-5375

Fan T, Miao J, Li Z, Cheng B (2019). Bio-inspired robust superhydrophobic-superoleophilic polyphenylene sulfide membrane for efficient oil/water separation under highly acidic or alkaline conditions. Journal of Hazardous Materials, 373: 11-22

Fan T, Qian Q, Hou Z, Liu Y, Lu M (2018). Preparation of smart and reversible wettability cellulose fabrics for oil/water separation using a facile and economical method. Carbohydrate Polymers, 200: 63-71

Feng J, Nguyen S T, Fan Z, Duong H M (2015). Advanced fabrication and oil absorption properties of super-hydrophobic recycled cellulose aerogels. Chemical Engineering Journal, 270: 168-175

Fu B, Yang Q, Yang F (2020). Flexible underwater oleophobic cellulose aerogels for efficient oil/water separation. ACS Omega, 5(14): 81818187

Foroughi F, Rezvani Ghomi E, Morshedi Dehaghi F, Borayek R, Ramakrishna S (2021). A review on the life cycle assessment of cellulose: From properties to the potential of making it a low carbon material. Materials (Basel), 14(4): 714

Gao X, Wen G, Guo Z (2018). Durable superhydrophobic and underwater superoleophobic cotton fabrics growing zinc oxide nanoarrays for application in separation of heavy/light oil and water mixtures as need. Colloids and Surfaces. A, Physicochemical and Engineering Aspects, 559: 115-126

Gore P M, Dhanshetty M, Balasubramanian K (2016). Bionic creation of nano-engineered Janus fabric for selective oil/organic solvent absorption. RSC Advances, 6(112): 111250-111260

Gore P M, Kandasubramanian B (2018). Heterogeneous wettable cotton based superhydrophobic Janus biofabric engineered with PLA/ functionalized-organoclay microfibers for efficient oil-water separation. Journal of Materials Chemistry. A, Materials for Energy and Sustainability, 6(17): 7457-7479

Gu J, Xiao P, Chen P, Zhang L, Wang H, Dai L, Song L, Huang Y, Zhang J, Chen T (2017). Functionalization of biodegradable PLA nonwoven fabric as superoleophilic and superhydrophobic material for efficient oil absorption and oil/water separation. ACS Applied Materials \& Interfaces, 9(7): 5968-5973

Guo X, Li C, Li C, Wei T, Tong L, Shao H, Zhou Q, Wang L, Liao Y (2019). G-CNTs/PVDF mixed matrix membranes with improved antifouling properties and filtration performance. Frontiers of Environmental Science \& Engineering, 13(6): 81

Gupta I, Rai C, Sondergeld C (2019). Study impact of sample treatment and in situ fluids on shale wettability measurement using NMR. Journal of Petroleum Science Engineering, 176: 352-361

Gupta P, Kandasubramanian B (2017). Directional fluid gating by Janus membranes with heterogeneous wetting properties for selective oilwater separation. ACS Applied Materials \& Interfaces, 9(22): 1910219113

Halim A, Lin K H, Enomae T (2020a). Biomimicking properties of cellulose nanofiber under ethanol/water mixture. Scientific Reports, 10(1): 21070

Halim A, Xu Y, Enomae T (2020b). Fabrication of cellulose sponge: effects of drying process and cellulose nanofiber deposition on the physical strength. ASEAN Journal of Chemical Engineering, 20(1): 1-10

Halim A, Xu Y, Lin K H, Kobayashi M, Kajiyama M, Enomae T (2019). Fabrication of cellulose nanofiber-deposited cellulose sponge as an oil-water separation membrane. Separation and Purification Technology, 224: 322-331

Han S, Sun Q, Zheng H, Li J, Jin C (2016). Green and facile fabrication of carbon aerogels from cellulose-based waste newspaper for solving organic pollution. Carbohydrate Polymers, 136: 95-100

Han S W, Kim H J, Woo T G, Jeong J H, Cha B J, Kim Y D (2018). Superhydrophobic fabric resistant to an aqueous surfactant solution as well as pure water for the selective removal of spill oil. ACS Applied Nano Materials, 1(9): 5158-5168

He X, Chen T, Jiang T, Wang C, Luan Y, Liu P, Liu Z (2021). Preparation and adsorption properties of magnetic hydrophobic cellulose aerogels based on refined fibers. Carbohydrate Polymers, 260: 117790

He Z, Zhang X, Batchelor W (2016). Cellulose nanofibre aerogel filter with tuneable pore structure for oil/water separation and recovery. 
RSC Advances, 6(26): 21435-21438

Hsieh C T, Hsu J P, Hsu H H, Lin W H, Juang R S (2016). Hierarchical oil-water separation membrane using carbon fabrics decorated with carbon nanotubes. Surface and Coatings Technology, 286: 148-154

Hu L, Liu Y, Wang Z, Zhou Y, Zhang Y, Liu Y, Li B (2020). A general in situ deposition strategy for synthesis of Janus composite fabrics with $\mathrm{Co}\left(\mathrm{CO}_{3}\right)_{0.5} \mathrm{OH} \cdot 0.11 \mathrm{H}_{2} \mathrm{O}$ nanoneedles for oil-water separation. ACS Applied Nano Materials, 3(4): 3779-3786

Huang J, Lyu S, Chen Z, Wang S, Fu F (2019a). A facile method for fabricating robust cellulose nanocrystal/ $/ \mathrm{SiO}_{2}$ superhydrophobic coatings. Journal of Colloid and Interface Science, 536: 349-362

Huang J, Lyu S, Fu F, Chang H, Wang S (2016). Preparation of superhydrophobic coating with excellent abrasion resistance and durability using nanofibrillated cellulose. RSC Advances, 6(108): 106194-106200

Huang J Y, Li S H, Ge M Z, Wang L N, Xing T L, Chen G Q, Liu X F, Al-Deyab S S, Zhang K Q, Chen T, Lai Y K (2015). Robust superhydrophobic $\mathrm{TiO}_{2} @$ fabrics for UV shielding, self-cleaning and oil-water separation. Journal of Materials Chemistry. A, Materials for Energy and Sustainability, 3(6): 2825-2832

Huang S, Wang D (2017). A simple nanocellulose coating for selfcleaning upon water action: molecular design of stable surface hydrophilicity. Angewandte Chemie (International ed. in English), 56(31): 9053-9057

Huang X, Gates I (2020). Apparent contact angle around the periphery of a liquid drop on roughened surfaces. Scientific Reports, 10(1): 8220

Huang Y, Zhan H, Li D, Tian H, Chang C (2019b). Tunicate cellulose nanocrystals modified commercial filter paper for efficient oil/water separation. Journal of Membrane Science, 591: 117362

Jeong H E, Kwak M K, Park C I, Suh K Y (2009). Wettability of nanoengineered dual-roughness surfaces fabricated by UV-assisted capillary force lithography. Journal of Colloid and Interface Science, 339(1): 202-207

Jiang W, Mao M, Qiu W, Zhu Y, Liang B (2017). Biomimetic superhydrophobic engineering metal surface with hierarchical structure and tunable adhesion: Design of microscale pattern. Industrial \& Engineering Chemistry Research, 56(4): 907-919

Kettunen M, Silvennoinen R J, Houbenov N, Nykänen A, Ruokolainen J, Sainio J, Pore V, Kemell M, Ankerfors M, Lindström T, Ritala M, Ras R H A, Ikkala O (2011). Photoswitchable superabsorbency based on nanocellulose aerogels. Advanced Functional Materials, 21(3): 510-517

Khan M Z, Baheti V, Militky J, Ali A, Vikova M (2018). Superhydrophobicity, UV protection and oil/water separation properties of fly ash/Trimethoxy(octadecyl)silane coated cotton fabrics. Carbohydrate Polymers, 202: 571-580

Kibler K M, Reinhart D, Hawkins C, Motlagh A M, Wright J (2018). Food waste and the food-energy-water nexus: A review of food waste management alternatives. Waste Management (New York, N.Y.), 74: 52-62

Kim D, Livazovic S, Falca G, Nunes S P (2019). Oil-water separation using membranes manufactured from cellulose/ionic liquid solutions. ACS Sustainable Chemistry \& Engineering, 7(6): 5649-5659

Koh J J, Lim G J H, Zhou X, Zhang X, Ding J, He C (2019). 3D-printed anti-fouling cellulose mesh for highly efficient oil/water separation applications. ACS Applied Materials \& Interfaces, 11(14): 1378713795

Korhonen J T, Huhtamäki T, Ikkala O, Ras R H (2013). Reliable measurement of the receding contact angle. Langmuir, 29(12): 3858 3863

Li S, Huang J, Chen Z, Chen G, Lai Y (2017a). A review on special wettability textiles: theoretical models, fabrication technologies and multifunctional applications. Journal of Materials Chemistry. A, Materials for Energy and Sustainability, 5(1): 31-55

Li S, Huang J, Ge M, Cao C, Deng S, Zhang S, Chen G, Zhang K, AlDeyab S S, Lai Y (2015). Robust flower-like TiO ${ }_{2} @$ cotton fabrics with special wettability for effective self-cleaning and versatile oil/ water separation. Advanced Materials Interfaces, 2(14): 1500220

Li Y, Dai S, John J, Carter K R (2013). Superhydrophobic surfaces from hierarchically structured wrinkled polymers. ACS Applied Materials \& Interfaces, 5(21): 11066-11073

Li Y, Zhang H, Fan M, Zheng P, Zhuang J, Chen L (2017b). A robust salt-tolerant superoleophobic alginate/graphene oxide aerogel for efficient oil/water separation in marine environments. Scientific Reports, 7(1): 46379

Li Y, Zhang H, Ma C, Yin H, Gong L, Duh Y, Feng R (2019a). Durable, cost-effective and superhydrophilic chitosan-alginate hydrogelcoated mesh for efficient oil/water separation. Carbohydrate Polymers, 226: 115279

Li Y, Zhu L, Grishkewich N, Tam K C, Yuan J, Mao Z, Sui X (2019b). $\mathrm{CO}_{2}$-responsive cellulose nanofibers aerogels for switchable oilwater separation. ACS Applied Materials \& Interfaces, 11(9): 93679373

Li Y S, Yan L, Xiang C B, Hong L J (2006). Treatment of oily wastewater by organic-inorganic composite tubular ultrafiltration (UF) membranes. Desalination, 196(1-3): 76-83

Li Z, Zhong L, Zhang T, Qiu F, Yue X, Yang D (2019c). Sustainable, flexible, and superhydrophobic functionalized cellulose aerogel for selective and versatile oil/water separation. ACS Sustainable Chemistry \& Engineering, 7(11): 9984-9994

Li Z, Qiu F, Yue X, Tian Q, Yang D, Zhang T (2021). Eco-friendly selfcrosslinking cellulose membrane with high mechanical properties from renewable resources for oil/water emulsion separation. Journal of Environmental Chemical Engineering, 9(5): 105857

Liu H, Gao S W, Cai J S, He C L, Mao J J, Zhu T X, Chen Z, Huang J Y, Meng K, Zhang K Q, Al-Deyab S S, Lai Y K (2016a). Recent progress in fabrication and applications of superhydrophobic coating on cellulose-based substrates. Materials (Basel), 9(3): 124

Liu J, Li P, Chen L, Feng Y, He W, Lv X (2016b). Modified superhydrophilic and underwater superoleophobic PVDF membrane with ultralow oil-adhesion for highly efficient oil/water emulsion separation. Materials Letters, 185: 169-172

Liu K, Cao M, Fujishima A, Jiang L (2014). Bio-inspired titanium dioxide materials with special wettability and their applications. Chemical Reviews, 114(19): 10044-10094

Liu M, Wang S, Jiang L (2013). Bioinspired multiscale surfaces with special wettability. MRS Bulletin, 38(5): 375-382

Liu M, Wang S, Wei Z, Song Y, Jiang L (2009). Bioinspired design of a superoleophobic and low adhesive water/solid interface. Advanced Materials, 21(6): 665-669 
Liu X, Zhou J, Xue Z, Gao J, Meng J, Wang S, Jiang L (2012). Clam's shell inspired high-energy inorganic coatings with underwater low adhesive superoleophobicity. Advanced Materials, 24(25): 34013405

Lu F, Chen Y, Liu N, Cao Y, Xu L, Wei Y, Feng L (2014). A fast and convenient cellulose hydrogel-coated colander for high-efficiency oil-water separation. RSC Advances, 4(61): 32544-32548

Lv Y, Li Q, Hou Y, Wang B, Zhang T (2019). Facile preparation of an asymmetric wettability Janus cellulose membrane for switchable emulsions' separation and antibacterial property. ACS Sustainable Chemistry \& Engineering, 7(17): 15002-15011

Lv Y, Xi X, Dai L, Tong S, Chen Z (2021). Hydrogel as a superwetting surface design material for oil/water separation: a review. Advanced Materials Interfaces, 8(7): 2002030

Ma Q, Cheng H, Fane A G, Wang R, Zhang H (2016). Recent development of advanced materials with special wettability for selective oil/water separation. Small, 12(16): 2186-2202

Mautner A, Lee K Y, Lahtinen P, Hakalahti M, Tammelin T, Li K, Bismarck A (2014). Nanopapers for organic solvent nanofiltration. Chemical Communications, 50(43): 5778-5781

Meng X, Dong Y, Zhao Y, Liang L (2020). Preparation and modification of cellulose sponge and application of oil/water separation. RSC Advances, 10(68): 41713-41719

Miao W, Jiao D, Wang C, Han S, Shen Q, Wang J, Han X, Hou T, Liu J, Zhang Y (2020). Ethanol-induced one-step fabrication of superhydrophobic-superoleophilic poly (vinylidene fluoride) membrane for efficient oil/water emulsions separation. Journal of Water Process Engineering, 34: 101121

Michel J C, Riviere L M, Bellon-Fontaine M N (2001). Measurement of the wettability of organic materials in relation to water content by the capillary rise method. European Journal of Soil Science, 52(3): 459467

Miller D J, Dreyer D R, Bielawski C W, Paul D R, Freeman B D (2017). Surface modification of water purification membranes. Angewandte Chemie (International ed. in English), 56(17): 4662-4711

Murakami D, Jinnai H, Takahara A (2014). Wetting transition from the Cassie-Baxter state to the Wenzel state on textured polymer surfaces. Langmuir, 30(8): 2061-2067

Nasution M A, Wibawa D S, Ahamed T, Noguchi R (2018). Comparative environmental impact evaluation of palm oil mill effluent treatment using a life cycle assessment approach: A case study based on composting and a combination for biogas technologies in North Sumatera of Indonesia. Journal of Cleaner Production, 184: 1028-1040

Nishimoto S, Bhushan B (2013). Bioinspired self-cleaning surfaces with superhydrophobicity, superoleophobicity, and superhydrophilicity. RSC Advances, 3(3): 671-690

Noamani S, Niroomand S, Rastgar M, Sadrzadeh M (2019). Carbonbased polymer nanocomposite membranes for oily wastewater treatment. NPJ Clean Water, 2(1): 20

Nosonovsky M, Bhushan B (2007). Hierarchical roughness optimization for biomimetic superhydrophobic surfaces. Ultramicroscopy, 107(10-11): 969-979

Padaki M, Surya Murali R, Abdullah M S, Misdan N, Moslehyani A, Kassim M A, Hilal N, Ismail F (2015). Membrane technology enhancement in oil-water separation. A review. Desalination, 357: 197-207

Panda A, Varshney P, Mohapatra S S, Kumar A (2018). Development of liquid repellent coating on cotton fabric by simple binary silanization with excellent self-cleaning and oil-water separation properties. Carbohydrate Polymers, 181: 1052-1060

Parker A R, Lawrence C R (2001). Water capture by a desert beetle. Nature, 414(6859): 33-34

Paul U C, Fragouli D, Bayer I S, Athanassiou A (2016). Functionalized cellulose networks for efficient oil removal from oil-water emulsions. Polymers, 8(2): 52

Peng H, Wang H, Wu J, Meng G, Wang Y, Shi Y, Liu Z, Guo X (2016a). Preparation of superhydrophobic magnetic cellulose sponge for removing oil from water. Industrial \& Engineering Chemistry Research, 55(3): 832-838

Peng H, Wu J, Wang Y, Wang H, Liu Z, Shi Y, Guo X (2016b). A facile approach for preparation of underwater superoleophobicity cellulose/ chitosan composite aerogel for oil/water separation. Applied Physics. A, Materials Science \& Processing, 122(5): 516

Peng S, Wang Y, Lan Y, Shi X, Zhang H, Qu H, Xu J (2020). Rational design of multifunctional superoleophobic/superhydrophilic, photocatalytic, and fire-retardant polyethylene terephthalate fabrics through layer-by-layer technique. Composites. Part B, Engineering, 200: 108264

Rasouli S, Rezaei N, Hamedi H, Zendehboudi S, Duan X (2021). Superhydrophobic and superoleophilic membranes for oil-water separation application: A comprehensive review. Materials \& Design, 204: 109599

Roger K, Cabane B (2012). Why are hydrophobic/water interfaces negatively charged? Angewandte Chemie (International ed. in English), 51(23): 5625-5628

Rohrbach K, Li Y, Zhu H, Liu Z, Dai J, Andreasen J, Hu L (2014). A cellulose based hydrophilic, oleophobic hydrated filter for water/oil separation. Chemical Communications, 50(87): 13296-13299

Runkle B R K, Suvoèarev K, Reba M L, Reavis C W, Smith S F, Chiu Y L, Fong B (2019). Methane emission reductions from the alternate wetting and drying of rice fields detected using the eddy covariance method. Environmental Science \& Technology, 53(2): 671-681

Salahi A, Gheshlaghi A, Mohammadi T, Madaeni S S (2010). Experimental performance evaluation of polymeric membranes for treatment of an industrial oily wastewater. Desalination, 262(1-3): 235-242

Sam E K, Liu J, Lv X (2021). Surface engineering materials of superhydrophobic sponges for oil/water separation: a review. Industrial \& Engineering Chemistry Research, 60(6): 2353-2364

Saththasivam J, Yiming W, Wang K, Jin J, Liu Z (2018). A novel architecture for carbon nanotube membranes towards fast and efficient oil/water separation. Scientific Reports, 8(1): 7418

Scanlon B R, Ruddell B L, Reed P M, Hook R I, Zheng C, Tidwell V C, Siebert S (2017). The food-energy-water nexus: Transforming science for society. Water Resources Research, 53(5): 3550-3556

Schutzius T M, Walker C, Maitra T, Schönherr R, Stamatopoulos C, Jung S, Antonini C, Eghlidi H, Fife J L, Patera A, Derome D, Poulikakos D (2017). Detergency and its implications for oil emulsion sieving and separation. Langmuir, 33(17): 4250-4259 
Semprebon C, McHale G, Kusumaatmaja H (2017). Apparent contact angle and contact angle hysteresis on liquid infused surfaces. Soft Matter, 13(1): 101-110

Shaghaleh H, Xu X, Wang S (2018). Current progress in production of biopolymeric materials based on cellulose, cellulose nanofibers, and cellulose derivatives. RSC Advances, 8(2): 825-842

Siebert S, Burke J, Faures J M, Frenken K, Hoogeveen J, Döll P, Portmann F T (2010). Groundwater use for irrigation: A global inventory. Hydrology and Earth System Sciences, 14(10): 18631880

Song B, Xu Q (2016). Highly hydrophobic and superoleophilic nanofibrous mats with controllable pore sizes for efficient oil/water separation. Langmuir, 32(39): 9960-9966

Su C, Yang H, Song S, Lu B, Chen R (2017). A magnetic superhydrophilic/oleophobic sponge for continuous oil-water separation. Chemical Engineering Journal, 309: 366-373

Suhas, Gupta V K, Carrott P J M, Singh R, Chaudhary M, Kushwaha S (2016). Cellulose: A review as natural, modified and activated carbon adsorbent. Bioresource Technology, 216: 1066-1076

Sun J, Li H, Huang Y, Zheng X, Liu Y, Zhuang J, Wu D (2019). Simple and affordable way to achieve polymeric superhydrophobic surfaces with biomimetic hierarchical roughness. ACS Omega, 4(2): 27502757

Tan H F, Ooi B S, Leo C P (2020). Future perspectives of nanocellulosebased membrane for water treatment. Journal of Water Process Engineering, 37: 101502

Teisala H, Tuominen M, Kuusipalo J (2014). Superhydrophobic coatings on cellulose-based materials: fabrication, properties, and applications. Advanced Materials Interfaces, 1(1): 1300026

Thakur V K, Voicu S I (2016). Recent advances in cellulose and chitosan based membranes for water purification: A concise review. Carbohydrate Polymers, 146: 148-165

Tian X, Jin H, Sainio J, Ras R H, Ikkala O (2014). Droplet and fluid gating by biomimetic janus membranes. Advanced Functional Materials, 24(38): 6023-6028

Tuteja A, Choi W, Ma M, Mabry J M, Mazzella S A, Rutledge G C, McKinley G H, Cohen R E (2007). Designing superoleophobic surfaces. Science, 318(5856): 1618-1622

Waghmare P R, Gunda N S K, Mitra S K (2014). Under-water superoleophobicity of fish scales. Scientific Reports, 4(1): 7454

Wang C F, Huang H C, Chen L T (2015a). Protonated melamine sponge for effective oil/water separation. Scientific Reports, 5(1): 14294

Wang C F, Yang S Y, Kuo S W (2017a). Eco-friendly superwetting material for highly effective separations of oil/water mixtures and oilin-water emulsions. Scientific Reports, 7(1): 43053

Wang F, Luo S, Xiao S, Zhang W, Zhuo Y, He J, Zhang Z (2020a). Enabling phase transition of infused lubricant in porous structure for exceptional oil/water separation. Journal of Hazardous Materials, 390: 122176

Wang F P, Zhao X J, Wahid F, Zhao X Q, Qin X T, Bai H, Xie Y Y, Zhong C, Jia S R (2021a). Sustainable, superhydrophobic membranes based on bacterial cellulose for gravity-driven oil/water separation. Carbohydrate Polymers, 253: 117220

Wang G, He Y, Wang H, Zhang L, Yu Q, Peng S, Wu X, Ren T, Zeng Z, Xue Q (2015b). A cellulose sponge with robust superhydrophilicity and under-water superoleophobicity for highly effective oil/water separation. Green Chemistry, 17(5): 3093-3099

Wang J, Chen H, Sui T, Li A, Chen D (2009). Investigation on hydrophobicity of lotus leaf: Experiment and theory. Plant Science, 176(5): 687-695

Wang J, Han F, Zhang S (2016a). Durably superhydrophobic textile based on fly ash coating for oil/water separation and selective oil removal from water. Separation and Purification Technology, 164: 138-145

Wang J, Wang A, Wang W (2017b). Robustly superhydrophobic/ superoleophilic kapok fiber with $\mathrm{ZnO}$ nanoneedles coating: Highly efficient separation of oil layer in water and capture of oil droplets in oil-in-water emulsions. Industrial Crops and Products, 108: 303-311

Wang K, Zhang T C, Wei B, Chen S, Liang Y, Yuan S (2021b). Durable CNTs reinforced porous electrospun superhydrophobic membrane for efficient gravity driven oil/water separation. Colloids and Surfaces. A, Physicochemical and Engineering Aspects, 608: 125342 Wang Q, Xie D, Chen J, Liu G, Yu M (2020b). Superhydrophobic paper fabricated via nanostructured titanium dioxide-functionalized wood cellulose fibers. Journal of Materials Science, 55(16): 7084-7094

Wang S, Li M, Lu Q (2010). Filter paper with selective absorption and separation of liquids that differ in surface tension. ACS Applied Materials \& Interfaces, 2(3): 677-683

Wang S, Liu K, Yao X, Jiang L (2015c). Bioinspired surfaces with superwettability: new insight on theory, design, and applications. Chemical Reviews, 115(16): 8230-8293

Wang S, Lu A, Zhang L (2016b). Recent advances in regenerated cellulose materials. Progress in Polymer Science, 53: 169-206

Wang Y, Uetani K, Liu S, Zhang X, Wang Y, Lu P, Wei T, Fan Z, Shen J, Yu J, Li S, Zhang Q, Li Q, Fan J, Yang N, Wang Q, Liu Y, Cao J, Li J, Chen W (2017c). Multifunctional bionanocomposite foams with a chitosan matrix reinforced by nanofibrillated cellulose. ChemNanoMat: Chemistry of Nanomaterials for Energy, Biology and More, 3(2): 98-108

Wang Z, Elimelech M, Lin S (2016c). Environmental applications of interfacial materials with special wettability. Environmental Science \& Technology, 50(5): 2132-2150

Wang Z, Jiang X, Cheng X, Lau C H, Shao L (2015d). Mussel-inspired hybrid coatings that transform membrane hydrophobicity into high hydrophilicity and underwater superoleophobicity for oil-in-water emulsion separation. ACS Applied Materials \& Interfaces, 7(18): 9534-9545

Wang Z, Liu G, Huang S (2016d). In situ generated Janus fabrics for the rapid and efficient separation of oil from oil-in-water emulsions. Angewandte Chemie (International ed. in English), 55(47): 14610 14613

Wang Z, Wang Y, Liu G (2016e). Rapid and efficient separation of oil from oil-in-water emulsions using a Janus cotton fabric. Angewandte Chemie (International ed. in English), 55(4): 1291-1294

Wenzel R N (1949). Surface roughness and contact angle. Journal of Physical Chemistry, 53(9): 1466-1467

Wong T S, Kang S H, Tang S K, Smythe E J, Hatton B D, Grinthal A, Aizenberg J (2011). Bioinspired self-repairing slippery surfaces with pressure-stable omniphobicity. Nature, 477(7365): 443-447

Wu Z, Zhang C, Peng K, Wang Q, Wang Z (2018). Hydrophilic/ 
underwater superoleophobic graphene oxide membrane intercalated by $\mathrm{TiO}_{2}$ nanotubes for oil/water separation. Frontiers of Environmental Science \& Engineering, 12(3): 15

Xie X, Liu L, Zhang L, Lu A (2020). Strong cellulose hydrogel as underwater superoleophobic coating for efficient oil/water separation. Carbohydrate Polymers, 229: 115467

Xu J, Ma C, Cao B, Bao J, Sun Y, Shi W, Yu S (2016). Pilot study on hydrophilized PVDF membranetreating produced water from polymer flooding for reuse. Process Safety and Environmental Protection, 104: 564-570

Xu T, Gao Z, Jia Y, Miao X, Zhu X, Lu J, Wang B, Song Y, Ren G, Li X (2021). Superhydrophobic corn straw as a versatile platform for oil/ water separation. Cellulose, 28(8): 4835-4846

Xu X, Long Y, Li Q, Li D, Mao D, Chen X, Chen Y (2019). Modified cellulose membrane with good durability for effective oil-in-water emulsion treatment. Journal of Cleaner Production, 211: 1463-1470

Yadav P, Ismail N, Essalhi M, Tysklind M, Athanassiadis D, Tavajohi N (2021). Assessment of the environmental impact of polymeric membrane production. Journal of Membrane Science, 622: 118987

Yang C, Wang Y, Fu H, Yang S, Zhu Y, Yue H, Jiang W, Liang B (2019a). A stable eco-friendly superhydrophobic/superoleophilic copper mesh fabricated by one-step immersion for efficient oil/ water separation. Surface and Coatings Technology, 359: 108-116

Yang H C, Hou J, Chen V, Xu Z K (2016). Janus membranes: Exploring duality for advanced separation. Angewandte Chemie (International ed. in English), 55(43): 13398-13407

Yang J, Xie A, Cui J, Chen Y, Lang J, Li C, Yan Y, Dai J (2020). An acid-alkali-salt resistant cellulose membrane by rapidly depositing polydopamine and assembling $\mathrm{BaSO}_{4}$ nanosheets for oil/water separation. Cellulose, 27(9): 5169-5178

Yang M, Liu W, Jiang C, Liu C, He S, Xie Y, Wang Z (2019b). Facile preparation of robust superhydrophobic cotton textile for selfcleaning and oil-water separation. Industrial \& Engineering Chemistry Research, 58(1): 187-194

Yi G, Fan X, Quan X, Chen S, Yu H (2019). Comparison of CNT-PVA membrane and commercial polymeric membranes in treatment of emulsified oily wastewater. Frontiers of Environmental Science \& Engineering, 13(2): 23

Youngblood J P, McCarthy T J (1999). Ultrahydrophobic polymer surfaces prepared by simultaneous ablation of polypropylene and sputtering of poly(tetrafluoroethylene) using radio frequency plasma. Macromolecules, 32(20): 6800-6806

Young T (1805). III. An essay on the cohesion of fluids. Philosophical Transactions of the Royal Society of London, 95: 65-87

Yue X, Li J, Zhang T, Qiu F, Yang D, Xue M (2017). In situ one-step fabrication of durable superhydrophobicsuperoleophilic cellulose/ LDH membrane with hierarchical structure for efficiency oil/water separation. Chemical Engineering Journal, 328: 117-123

Yue X, Zhang T, Yang D, Qiu F, Li Z (2018a). Hybrid aerogels derived from banana peel and waste paper for efficient oil absorption and emulsion separation. Journal of Cleaner Production, 199: 411419

Yue X, Zhang T, Yang D, Qiu F, Li Z, Zhu Y, Yu H (2018b). Oil removal from oily water by a low-cost and durable flexible membrane made of layered double hydroxide nanosheet on cellulose support. Journal of
Cleaner Production, 180: 307-315

Yue X, Zhang T, Yang D, Qiu F, Li Z (2018c). Janus ZnO-cellulose/ $\mathrm{MnO}_{2}$ hybrid membranes with asymmetric wettability for highlyefficient emulsion separations. Cellulose, 25(10): 5951-5965

Zahid M, Heredia-Guerrero J A, Athanassiou A, Bayer I S (2017). Robust water repellent treatment for woven cotton fabrics with ecofriendly polymers. Chemical Engineering Journal, 319: 321-332

Zarghami S, Mohammadi T, Sadrzadeh M, Van der Bruggen B (2019). Superhydrophilic and underwater superoleophobic membranes-A review of synthesis methods. Progress in Polymer Science, 98: 101166

Zhai L, Berg M C, Cebeci F C, Kim Y, Milwid J M, Rubner M F, Cohen R E (2006). Patterned superhydrophobic surfaces: toward a synthetic mimic of the Namib Desert beetle. Nano Letters, 6(6): 1213-1217

Zhan H, Peng N, Lei X, Huang Y, Li D, Tao R, Chang C (2018). UVinduced self-cleanable $\mathrm{TiO}_{2} /$ nanocellulose membrane for selective separation of oil/water emulsion. Carbohydrate Polymers, 201: 464470

Zhang H, Li Y, Lu Z, Chen L, Huang L, Fan M (2017a). A robust superhydrophobic $\mathrm{TiO}_{2}$ NPs coated cellulose sponge for highly efficient oil-water separation. Scientific Reports, 7(1): 9428

Zhang K, Wang M, Wu M, Wu Q, Liu J, Yang J, Zhang J (2020a). Fabrication of robust superhydrophobic filter paper for oil/water separation based on the combined octadecanoyl chain bonding and polymer grafting via surface-initiated ATRP. Cellulose, 27(1): 469480

Zhang M, Wang C, Wang S, Li J (2013). Fabrication of superhydrophobic cotton textiles for water-oil separation based on dropcoating route. Carbohydrate Polymers, 97(1): 59-64

Zhang S, Huang J, Chen Z, Lai Y (2017b). Bioinspired special wettability surfaces: from fundamental research to water harvesting applications. Small, 13(3): 1602992

Zhang X, Xiao F, Feng Q, Zheng J, Chen C, Chen H, Yang W (2020b). Preparation of $\mathrm{SiO}_{2}$ nanoparticles with adjustable size for fabrication of $\mathrm{SiO}_{2}$ /PMHS ORMOSIL superhydrophobic surface on cellulosebased substrates. Progress in Organic Coatings, 138: 105384

Zhang Y, Wang X, Wang C, Zhai H, Liu B, Zhao X, Fang D, Wei Y (2019a). Facile preparation of flexible and stable superhydrophobic non-woven fabric for efficient oily wastewater treatment. Surface and Coatings Technology, 357: 526-534

Zhang Z, Yu H, Guo J, Bai Z, Zhang S, Zhang Y, Wang J (2019b). pHResponsive smart non-woven fabrics (NWFs) with double switchable wettability between superhydrophilicity-superhydrophobicitysuperhydrophilicity to oil/water separation. New Journal of Chemistry, 43(17): 6712-6720

Zhao S, Tao Z, Chen L, Han M, Zhao B, Tian X, Wang L, Meng F (2021). An antifouling catechol/chitosan-modified polyvinylidene fluoride membrane for sustainable oil-in-water emulsions separation. Frontiers of Environmental Science \& Engineering, 15(4): 63

Zhou K, Zhang Q G, Li H M, Guo N N, Zhu A M, Liu Q L (2014). Ultrathin cellulose nanosheet membranes for superfast separation of oil-in-water nanoemulsions. Nanoscale, 6(17): 10363-10369

Zhou S, You T, Zhang X, Xu F (2018). Superhydrophobic cellulose nanofiber-assembled aerogels for highly efficient water-in-oil emulsions separation. ACS Applied Nano Materials, 1(5): 2095-2103 
Zhou X, Zhang Z, Xu X, Guo F, Zhu X, Men X, Ge B (2013). Robust and durable superhydrophobic cotton fabrics for oil/water separation. ACS Applied Materials \& Interfaces, 5(15): 7208-7214

Zhu D, Xia Y, Yang J, Chen B, Guo S, Li C (2017). One-step removal of insoluble oily compounds and water-miscible contaminants from water by underwater superoleophobic graphene oxide-coated cotton. Cellulose, 24(12): 5605-5614

Zhu L, Li H, Yin Y, Cui Z, Ma C, Li X, Xue Q (2020). One-step synthesis of a robust and anti-oil-fouling biomimetic cactus-like hierarchical architecture for highly efficient oil/water separation. Environmental Science. Nano, 7(3): 903-911

Zhuang G L, Wu S Y, Lo Y C, Chen Y C, Tung K L, Tseng H H (2020). Gluconacetobacter xylinus synthesized biocellulose nanofiber membranes with superhydrophilic and superoleophobic underwater properties for the high-efficiency separation of oil/water emulsions. Journal of Membrane Science, 605: 118091 